\title{
Daylight performance of a microstructured prismatic window film in deep open plan offices
}

\author{
Andrew McNeil, Eleanor S. Lee*, Jacob C. Jonsson \\ Building Technologies and Urban Systems Division, Energy Technologies Area, Lawrence Berkeley \\ National Laboratory, Mailstop 90-3111, 1 Cyclotron Road, Berkeley, CA 94720 USA
}

\begin{abstract}
Daylight redirecting systems with vertical windows have the potential to offset lighting energy use in deep perimeter zones. A microstructured prismatic film designed for such use was characterized using goniophotometric measurements and ray tracing simulations. The synthetically-generated bidirectional scattering distribution function (BSDF) data were shown to have good agreement with limited measured data for normal incident angles $\left(0-60^{\circ}\right)$. Measured data indicated that the prismatic film was most efficient when vertical angles of incidence were between $18-35^{\circ}$ and within $\pm 45^{\circ}$ of normal incidence to the plane of the window so maximum energy savings across the full depth of the zone occurred over the equinox to winter solstice period. Annual lighting energy use and visual comfort in a deep open plan office zone were evaluated using the Radiance three-phase method in several climates and for south and east-facing window orientations. Lighting energy savings were $39-43 \%$ for a $12 \mathrm{~m}(40 \mathrm{ft})$ deep south-facing perimeter zone compared to the same zone with no lighting controls. The prismatic film with and without a diffuser controlled glare for views parallel to the window but produced glare for seated viewpoints looking toward the window. At mature market costs, the system was projected to have a simple payback of 2-6 years. Technical challenges encountered throughout the evaluation led to improvements in measurement and modeling tools and stressed the importance of having accurate input data for product development.
\end{abstract}

Keywords: Daylighting; prismatic film; microstructured film;bidirectional scattering distribution function; complex fenestration systems

\section{Introduction}

There has been significant research dedicated to developing micro- and macroscopic materials and systems for the purpose of redirecting sunlight and diffuse skylight deeper into the building interior. Since lighting energy use represents 13\% of the total primary energy used by buildings in the United States or 5.42 quad (quadrillion $=10^{15} \mathrm{Btu}$ ) in 2010 (D\&R International, 2012), such innovative technologies can play a significant role towards aggressive energy-efficiency and greenhouse gas emission reduction goals. Microstructured devices include angular selective coatings on glass and holographic optical elements (HOEs) (Smith and Granqvist, 2010; Sullivan et al., 1998; Papamichael et al., 1994). Static macroscopic systems for vertical windows include prismatic optical elements (POEs), mirrored louvers, lasercut panels, and enhanced light shelves (Wadsworth, 1903; Bartenbach et al., 1987; Moensch et al., 1987; Ruck et al. 2000; Andersen and Thuot, 2012; Beltrán et al., 1997; Rogers et al., 2004). Motorized solar tracking systems have also been developed for sidelighting applications (e.g., Bartenbach, 1994). More optimized and complex solutions have involved roof-mounted, sun-tracking heliostats coupled to skylights, atria and light-guiding mirrored ducts (Whitehead, 2013), or fiberoptics systems (Muhs et al., 2007). For both static

* Corresponding author. Tel.: 510486 4997; fax: 510486 4089. E-mail address: eslee@lbl.gov (E.S. Lee). 
and dynamic systems, the technical challenge has been how to achieve significant redirection of daylight for a broad range of incident angles without causing discomfort glare.

Given the call for low-cost solutions that can meet aggressive building energy efficiency and carbon emission reduction goals in the near term, interest in surface relief microstructured windows films such as holographic diffusers, holographic optical elements, diffraction gratings, and prismatic structures has been renewed, particularly if applicable to the retrofit market. Such films can be made through embossing with surface textures of depths between 10 nanometers up to 200 microns. Films are manufactured in a cleanroom environment via roll-to-roll processes with widths that are applicable to large-area windows (e.g., $2 \mathrm{~m}$ ). The substrate film can be composed of multiple layers of acrylic (polymethyl methacrylate or PMMA), polycarbonate, or other materials that are not susceptible to degradation under prolonged exposure to sunlight. The daylight film can be combined potentially with solar control films in a multilayer system that achieves both solar and daylight control.

As with most innovations, creating the volume manufacturing capability for an emerging technology requires significant capital investments so launching a venture enterprise needs to be justified carefully. Quantifying technical and market potential is a critical part of decisionmaking. Until recently, the tools for characterizing performance impacts have been limited, making it difficult to build an economic case for widespread deployment of daylighting technologies by potential adopters (building owners, utility emerging technology programs, regulators) and difficult to identify the key markets where their application would be most promising.

Significant progress has been made within the R\&D community toward more routine and more accurate evaluations of the energy and comfort impacts of optically-complex daylighting systems. First, measurements of angularly-resolved transmittance and reflectance properties of light-scattering materials and coplanar systems have been facilitated using scanning goniophotometers (Apian-Bennewitz and von der Hardt, 1998; Andersen and de Boer, 2006; Andersen et al., 2010). Second, the algorithms defined by Klems (1994a, 1994b) to determine solar heat gains through multi-layered fenestration systems involving scattering layers have been incorporated and extended to the calculation of daylight illuminance and luminance within the Radiance simulation tool (Ward et al., 2011, McNeil and Lee, 2012). Assessments of daylighting systems now take a fraction of the time that was needed in the past, opening up opportunities to leverage the power of parallel cluster computing for both detailed assessments of performance impacts as well as improvements to technological designs.

The primary objective of this study was to evaluate the performance of prototype microstructured daylighting films, which have become more economically viable given advances in roll-to-roll manufacturing. The study evaluates two prototype designs in a south- or east-facing, $14.6 \mathrm{~m}$ deep open plan office zone with daylight-responsive electric lighting in four climates. Annual lighting energy use and visual comfort performance is compared to that of a conventional shading system. Detailed data are presented as a means of relating temporal and spatial performance to the angle-dependent optical properties of the prototypes. As a developer of measurement and modeling tools, a second underlying objective of this study was to identify the various challenges encountered in the characterization and modeling of prototype systems during the early stages of product development and then define potential comprehensive solutions for addressing the challenges. As with all R\&D activities, assessments must be conducted within real world time and resource constraints which in turn have impacts on the accuracy of the outcomes. This study examines the impact of measured and synthetically generated bidirectional scattering distribution function (BSDF) input data on modeled results, providing limited insights as to the importance of having accurate input data for product development. Enabling accurate characterization of optically-complex fenestration systems within tight resource constraints is identified as a key critical challenge for the buildings industry. 


\section{Method}

\subsection{Perimeter zone configuration}

A $178.5 \mathrm{~m}^{2}\left(1920 \mathrm{ft}^{2}\right)$ furnished, open plan perimeter office zone was modeled using the Radiance simulation software (Ward and Shakespeare, 1998). The zone's overall dimensions of $12.2 \mathrm{~m}$ wide by 14.6 $\mathrm{m}$ deep (40x48 ft) were based on a modified version of the US Department of Energy (DOE) large office commercial building prototype (Deru et al., 2011). The zone was made purposely deep to assess the ability of the prototype daylight redirecting systems to deliver daylight beyond the typical perimeter daylight zone of one to two times the head height of the window (Table 1). The ceiling height of $2.7 \mathrm{~m}(9 \mathrm{ft}$ ) is typical of US commercial office building construction. The height of the furniture was low (1-1.4 m, 3.3-4.5 ft) to reflect common trends in the industry to lower workstation heights in order to provide all occupants with access to outdoor views. Surface reflectances were typical of commercial office finishes. No exterior obstructions were modeled.

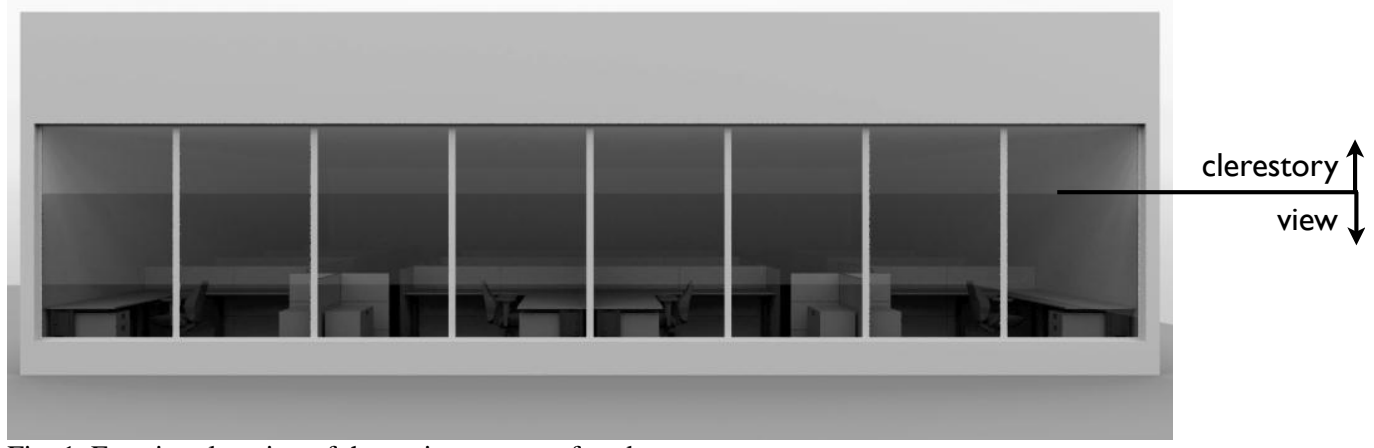

Fig. 1. Exterior elevation of the perimeter zone façade.
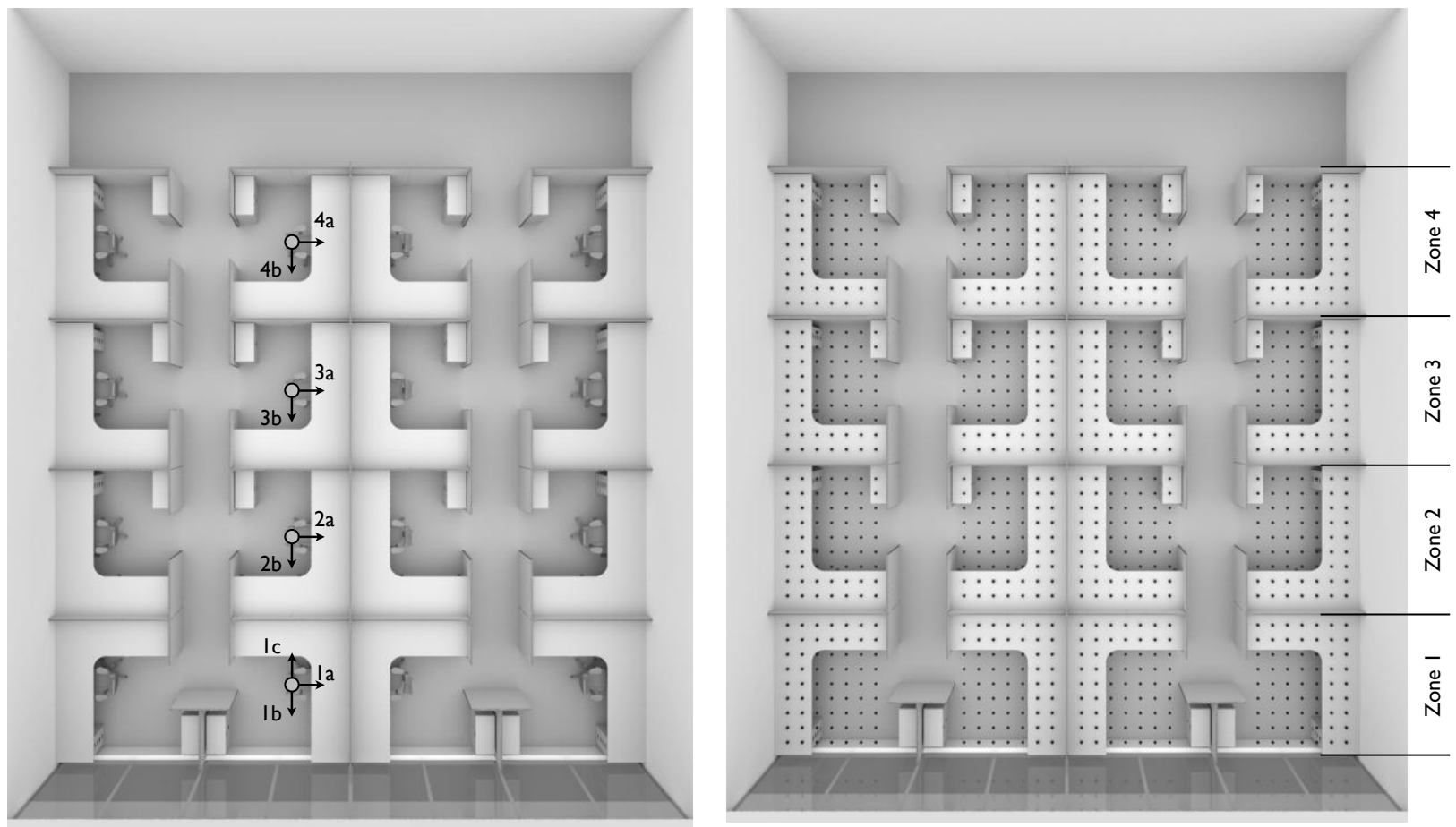

Fig. 2. Floor plan view of the open plan perimeter office zone showing a) locations and directions of the nine views used for glare assessments (left image) and b) locations of the work plane illuminance grid points, where the four zones are divided by the cubical partitions parallel to the window (right image). 
Table 1

Summary of modeling assumptions

\begin{tabular}{|c|c|c|}
\hline & Dimensions (SI) & Dimensions (IP) \\
\hline Zone dimensions & $12.2 \mathrm{~m}$ wide, $14.6 \mathrm{~m}$ deep, $2.7 \mathrm{~m}$ high & $40 \times 48 \times 9 \mathrm{ft}$ \\
\hline Floor area & $178.5 \mathrm{~m}^{2}$ & $1920 \mathrm{ft}^{2}$ \\
\hline Floor-to-floor height & $3.96 \mathrm{~m}$ & $13 \mathrm{ft}$ \\
\hline Furnishings & $\begin{array}{l}\text { (16) } 1.83 \times 2.44 \mathrm{~m} \text { cubicles with } 1 \mathrm{~m} \text { high } \\
\text { partitions parallel to the window and } 1.4 \mathrm{~m} \\
\text { high partitions perpendicular to the window }\end{array}$ & $\begin{array}{l}\text { (16) } 6 \times 8 \mathrm{ft} \text { cubicles with } 3.3 \mathrm{ft} \text { high } \\
\text { partitions parallel to the window and } 4.5 \mathrm{ft} \\
\text { high partitions perpendicular to the window }\end{array}$ \\
\hline $\begin{array}{l}\text { Reflectance of indoor } \\
\text { surfaces (Rvis) }\end{array}$ & \multicolumn{2}{|c|}{ Walls: 0.65 , floor: 0.3 , ceiling: 0.8 , desks: 0.4 , partitions: 0.45 , chairs: 0.2} \\
\hline Ground reflectance & \multicolumn{2}{|l|}{ Rvis $=0.1$, uniformly diffusing } \\
\hline Obstructions (trees, etc.) & \multicolumn{2}{|l|}{ None } \\
\hline Upper clerestory windows & $\begin{array}{l}\text { (5) } 2.44 \mathrm{~m} \text { wide } \times 0.72 \mathrm{~m} \text { tall, sill height } \\
1.98 \mathrm{~m} \text { above the floor }\end{array}$ & $\begin{array}{l}\text { (5) } 8 \mathrm{ft} \text { wide } \times 2.375 \mathrm{ft} \text { tall, sill height } 6.5 \mathrm{ft} \\
\text { above the floor }\end{array}$ \\
\hline Lower view windows & $\begin{array}{l}\text { (5) } 2.44 \mathrm{~m} \text { wide, } 1.65 \mathrm{~m} \text { tall, sill height } 0.37 \\
\mathrm{~m} \text { above the floor }\end{array}$ & $\begin{array}{l}\text { (5) } 8 \mathrm{ft} \text { wide, } 5.42 \mathrm{ft} \text { tall, sill height } 1.21 \mathrm{ft} \\
\text { above the floor }\end{array}$ \\
\hline Window frames & $76.2 \mathrm{~mm}$ & 3 inches \\
\hline Venetian blind & $\begin{array}{l}\text { Venetian blind over full height, slat width: } \\
25.4 \mathrm{~mm} \text {, slat to slat distance: } 20 \mathrm{~mm}, 45^{\circ} \\
\text { slat angle, Rvis }=0.80 \text {. }\end{array}$ & $\begin{array}{l}\text { Venetian blind over full height, slat width: } 1 \\
\text { inch, slat to slat distance: } .79 \text { inch, } 45^{\circ} \text { slat } \\
\text { angle, Rvis }=0.80\end{array}$ \\
\hline $\begin{array}{l}\text { Window-to-wall area ratio } \\
\text { (WWR) }\end{array}$ & \multicolumn{2}{|l|}{$\begin{array}{l}\text { Total: WWR=0.60; Upper: WWR }=0.183 \text {; } \\
\text { Lower: WWR }=0.417\end{array}$} \\
\hline Façade orientation & \multicolumn{2}{|l|}{ South and east } \\
\hline Lighting control zones: & Distance from window $(\mathrm{m})$ : & Distance from window $(\mathrm{ft})$ : \\
\hline Zone 1 & $0.00-3.05 \mathrm{~m}$ & $0-10 \mathrm{ft}$ \\
\hline Zone 2 & $3.05-6.10 \mathrm{~m}$ & $10-20 \mathrm{ft}$ \\
\hline Zone 3 & $6.10-9.15 \mathrm{~m}$ & $20-30 \mathrm{ft}$ \\
\hline Zone 4 & $9.15-12.20 \mathrm{~m}$ & $30-40 \mathrm{ft}$ \\
\hline Illuminance setpont & $500 \operatorname{lux}$ & $46.47 \mathrm{fc}$ \\
\hline Simulation timestep & \multicolumn{2}{|l|}{1 hour } \\
\hline Zone illuminance level & $\begin{array}{l}\text { Average illuminance of } 0.30-\mathrm{m} \text { grid of } \\
\text { points at desk height }(0.76 \mathrm{~m}) \text { per zone }\end{array}$ & $\begin{array}{l}\text { Average illuminance of } 1 \mathrm{ft} \text { grid of points at } \\
\text { desk height }(2.5 \mathrm{ft}) \text { per zone }\end{array}$ \\
\hline Lighting schedule & \multicolumn{2}{|l|}{$\begin{array}{l}8: 00 \text { - 18:00 Local Time, all week days of } \\
\text { the year }\end{array}$} \\
\hline Lighting energy use & \multicolumn{2}{|l|}{$\begin{array}{l}10-100 \% \text { light output, } 20-100 \% \text { power, } 3 \% \\
\text { standby power }\end{array}$} \\
\hline \multirow[t]{2}{*}{ View locations: } & $1.22 \mathrm{~m}$ above the floor & $4 \mathrm{ft}$ above the floor \\
\hline & Distance from window $(\mathrm{m})$ : & Distance from window $(\mathrm{ft})$ : \\
\hline View 1 & $\begin{array}{l}1.5 \mathrm{~m} \text {, looking at window, side wall, and } \\
\text { rear wall }\end{array}$ & $\begin{array}{l}5 \mathrm{ft} \text {, looking at window, side wall, and rear } \\
\text { wall }\end{array}$ \\
\hline View 2 & $4.6 \mathrm{~m}$, looking at window and side wall & $15 \mathrm{ft}$, looking at window and side wall \\
\hline View 3 & $7.6 \mathrm{~m}$, looking at window and side wall & $25 \mathrm{ft}$, looking at window and side wall \\
\hline View 4 & $10.7 \mathrm{~m}$, looking at window and side wall & $35 \mathrm{ft}$, looking at window and side wall \\
\hline Image resolution & $800 \times 800$ pixels & \\
\hline BSDF basis & 146x146 modified horizontal Klems basis & \\
\hline
\end{tabular}

\subsection{Window configurations}

The façade was divided into upper daylight and lower view windows (Fig. 1). The upper daylight windows form a continuous strip of clerestory windows with a sill height of $1.98 \mathrm{~m}(6.5 \mathrm{ft})$ above the floor. These windows have a center-of-glass visible transmittance (Tvis) of 0.61 and a window-to-exterior-wall area ratio (WWR) of 0.18 . The lower view windows were also continuous in width with a height of $1.65 \mathrm{~m}(5.4$ $\mathrm{ft}$ ) and sill height of $0.37 \mathrm{~m}(1.2 \mathrm{ft})$ above the floor (WWR=0.42). The center-of-glass transmittance was Tvis=0.29. The makeup and properties of the modeled window are given in Table 2 .

The window configurations were defined by one reference case and two test cases (Table 3): 
- The reference case ("VB") was defined with interior white Venetian blinds covering both the upper and lower windows. The Venetian blinds were comprised of curved, concave down, matte, $1.6 \mathrm{~cm}$ (0.63 in.) wide white slats (Rvis $=0.80$, Tvis $=0.05)$ spaced $1.2 \mathrm{~cm}(0.47 \mathrm{in}$.) apart and set at a $45^{\circ}$ tilt angle (lower edge of slat toward the exterior).

- The first test case ("P1") uses a daylighting film on the upper windows and the same Venetian blinds as the reference case on the lower windows.

- The second test case ("P2") consists of daylighting and diffusing films on the upper windows and the same Venetian blinds as the reference case on the lower windows.

The two test cases involved a microstructured, asymmetrical, multi-sided refractive prismatic film (3M Daylight Redirecting Film, Padiyath et al. 2013). The film consisted of an orderly array of linear protrusions between 50-250 micrometers high. Each protrusion can be described as a four-sided prism where sunlight from an incident range of $5-80^{\circ}$ is refracted by total internal reflection. The film can be manufactured using roll-to-roll processing methods and then adhered to a vertical window as a retrofit or replacement measure. Views through the film are distorted, not clear. The film itself is colorless.

The first daylight-redirecting system ("P1") consisted of this film adhered to the indoor surface (\#4) of the upper clerestory window. The second daylight-redirecting system ("P2") used the same daylightredirecting film and a second light diffusing film (3M Fasara ${ }^{\mathrm{TM}}$ Mat Crystal 2 SH2MACRX2; Hao et al. 2012) in a triple-pane low-e window. The low-e coating was on surface $\# 2$, the daylight-redirecting film was adhered to surface \#4 and the light diffusing film was adhered to surface \#5; the base glazing layers were the same used in the reference case (see Table 2).

Table 2

Window composition and center-of-glass properties.

\begin{tabular}{|c|c|c|c|c|}
\hline & Description & Tvis & U-value $\left(\mathrm{W} / \mathrm{m}^{2} \mathrm{~K}\right)$ & SHGC \\
\hline \multirow[t]{2}{*}{ Upper window } & Layer 1: 6 mm low-e glass (Viracon VRE1-67) & 0.606 & 1.693 & 0.449 \\
\hline & Layer 2: $6 \mathrm{~mm}$ clear glass & & & \\
\hline \multirow[t]{2}{*}{ Lower window } & Layer 1: 6 mm low-e glass (Viracon VRE1-30) & 0.290 & 1.855 & 0.302 \\
\hline & Layer 2: $6 \mathrm{~mm}$ clear glass & & & \\
\hline \multirow[t]{2}{*}{ P1 } & Layer 1: 6 mm low-e glass (Viracon VRE1-67) & 0.532 & 1.693 & 0.449 \\
\hline & Layer 2: $6 \mathrm{~mm}$ clear glass, prismatic film on surface 4 & & & \\
\hline \multirow[t]{3}{*}{$\mathrm{P} 2$} & Layer 1: 6 mm low-e glass (Viracon VRE1-67) & 0.427 & 1.855 & 0.302 \\
\hline & Layer 2: $6 \mathrm{~mm}$ clear glass, prismatic film on surface 4 & & & \\
\hline & Layer 3: $6 \mathrm{~mm}$ clear glass, diffusing film on surface 5 & & & \\
\hline
\end{tabular}

Table 3

Shading condition for simulation cases.

\begin{tabular}{lll}
\hline Case & Daylight (upper) window condition & View (lower) window condition \\
\hline VB & White Venetian blind with $45^{\circ}$ slat tilt angle & White Venetian blind with $45^{\circ}$ slat tilt angle \\
P1 & P1 system & White Venetian blind with $45^{\circ}$ slat tilt angle \\
P2 & P2 system & White Venetian blind with $45^{\circ}$ slat tilt angle \\
\hline
\end{tabular}

\subsection{Radiance simulations}

The Radiance three-phase method was used to perform annual daylight simulations to evaluate both lighting energy savings and visual comfort (Ward et al. 2011). This method separates light transport into three phases or matrices that: a) relates solid angles or patches from a subdivided hemispherical sky to incident directions on the window (daylight matrix), b) describes the outgoing angular and intensity distribution of reflected and transmitted flux from the fenestration system as a function of incident angle (bidirectional scattering distribution function (BSDF) matrix), and c) relates the outgoing directions from the window to the desired locations in the interior (view matrix). The sky vector assigns luminance values 
to patches representing the sky directions. The resultant illumination is obtained by performing matrix multiplication of the three phases and the sky matrix for each time step. This approach enables quick computation of the annual performance of any arbitrary optically-complex fenestration system. Facades can be changed without simulating the entire light path, just substituting a new sky vector or fenestration BSDF matrix. The dctimestep tool within Radiance (version 4.0) calls this calculation for each time step to compute illuminance and luminance quantities defined by the user. Appendix A1 lists the Radiance parameters used for the simulations.

To generate the sky vector, direct normal irradiance and diffuse horizontal irradiance values are taken from TMY2 weather data. The program gendaylit uses the irradiance data to generate a Perez sky definition for Radiance. The Radiance program genskyvec divides the sky into Tregenza or Reinhart patches and computes the average luminance of the patch. This study used a highly resolved sky to improve accuracy of the calculation (Reinhart MF:4 subdivision scheme with 2305 patches).

The daylight matrix was generated using the Radiance rtcontrib program for a window without near- or farfield obstructions. The exterior ground was uniformly diffusing with a reflectance of 0.1 .

The view matrices were defined for nine rendered views at a height of $1.2 \mathrm{~m} \mathrm{(4ft)} \mathrm{above} \mathrm{the} \mathrm{floor} \mathrm{and} \mathrm{for}$ four zones of workplane illuminance sensor points. The nine views were used to assess daylight discomfort glare in the space (Fig. 2a, Table 1). Workplane illuminance sensor points were defined by a grid of points spaced $0.30 \mathrm{~m}(1 \mathrm{ft}$ ) apart across each of the four zones (Fig. 2b).

The BSDF matrix was defined using Window 6.3.3 (Mitchell et al. 2008) where individual glazing layers were selected from the International Glazing Database (LBNL, 2013) and the BSDF data for individual shading and daylighting layers were defined using measured data and/or ray-tracing tools as described below. Window 6 was used to combine the glass and shading or daylighting layers to form a single window system whose whole window BSDF were then output by Window 6 in an XML file format for use by Radiance.

The Radiance genBSDF tool (McNeil et al., 2013) (and other ray tracing tools like TracePro) can produce full BSDF datasets, requiring inputs of geometry and material data. In this study, the geometry of the prismatic film was provided by the manufacturer and modeled in Radiance using genBSDF. The film, adhesive, and $6 \mathrm{~mm}$ glass substrate were all modeled as dielectric volumes with refractive indices of 1.511 for the film, 1.497 for the adhesive and 1.52 for the glass. ${ }^{1}$ Section 3.1 discusses the derivation of the BSDF dataset in more detail.

The BSDF for the diffusing film was generated using goniophotometric measurements. Since the film is isotropic, only one measurement per incident theta band was required (Klems coordinate system has nine theta bands, so nine incident angles each for front and back of the sample).

The BSDF for the Venetian blind was derived from the built-in Window 6 Venetian blind model, where the surfaces of the slats were modeled as hemispherically diffusing (Lambertian).

For all cases, the synthetic BSDFs used a modified version of the full Klems angle basis which provides a clear division between upward and downward flux (Fig. 3). Flux just above horizontal provides deep daylight penetration while flux just below horizontal is most likely to cause glare. In the full Klems angle basis, flux just above and just below horizontal are lumped into the same patch. The horizontally divided angle basis used in this analysis separates flux just above and flux just below into separate patches.

\footnotetext{
${ }^{1}$ Radiance parameters used for sampling were -ab 2 -ad 700.
} 


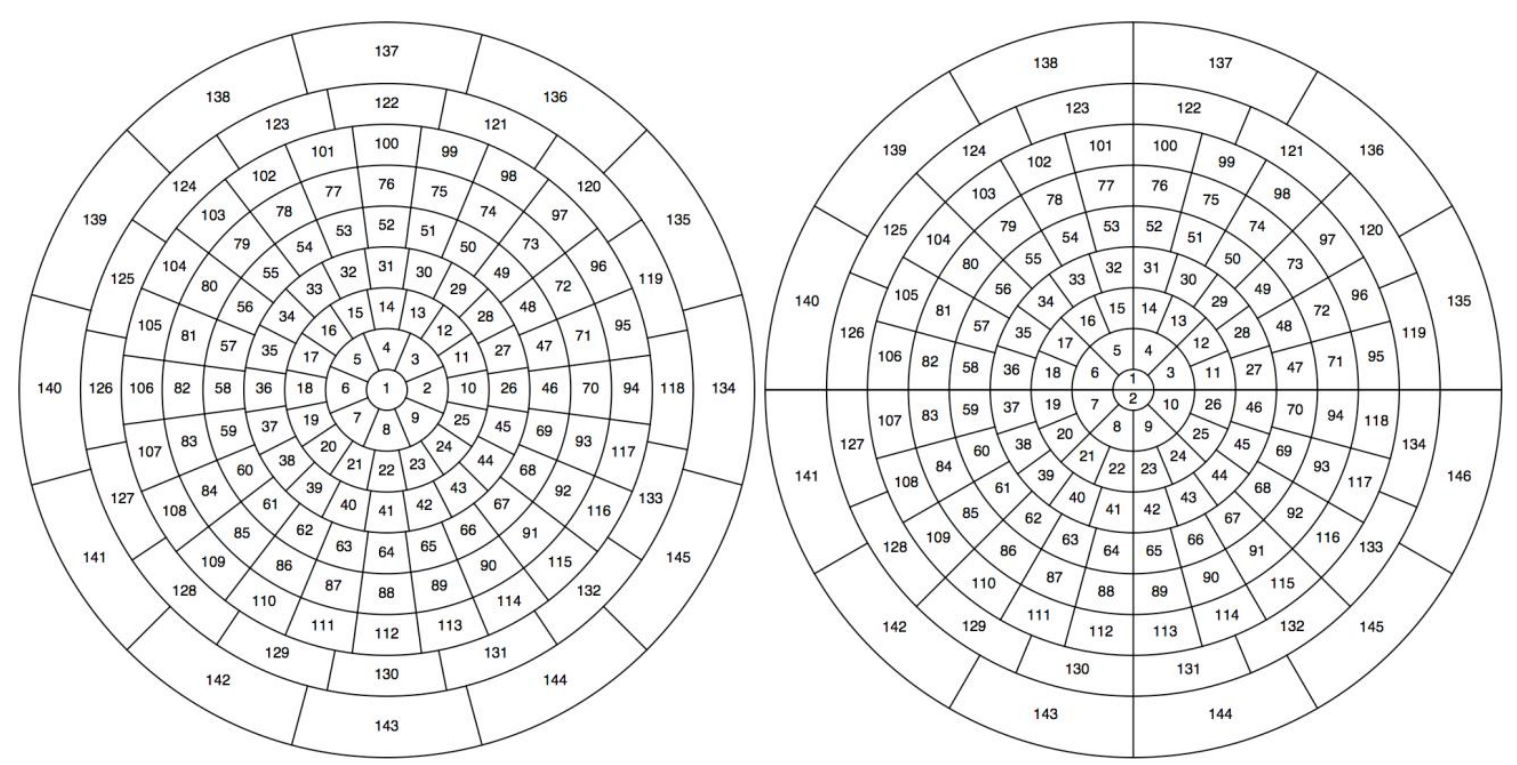

Fig. 3. Diagrams showing divisions of the full Klems angle basis (left) and the modified Klems horizontal angle basis (right).

\subsection{Lighting system and energy use}

The perimeter zone was divided into four $3.05 \mathrm{~m}$ (10 ft) deep lighting control zones parallel to the window (Fig. 2b). Dimming was proportional to available daylight, where the average hourly daylight illuminance was determined in each zone from a $0.31 \mathrm{~m}(1 \mathrm{ft})$ grid of points.

Given the evolving dimmable lighting market and diversity of lighting solutions (fluorescent and LED lighting, ballast efficiency, digitally addressable lighting controls, etc.), the lighting system was first modeled as an ideal continuous dimmable system with 0-100\% light output for a corresponding 0-100\% power use. The setpoint workplane illuminance was defined by the Illuminating Engineering Society of North America (IESNA) Lighting Handbook recommendations for open plan offices with intermittent (500 lux) visual display terminal (VDT) use (Rea, 2002).

Total perimeter zone lighting energy use was determined from the average of the four zones and expressed as fractional lighting energy use where 1.0 is the lights on at full power and 0.0 is with the lights off all hours. Annual fractional lighting energy use was determined for daytime office work hours from 8:0018:00 local time (LT) for all days of the year.

The annual fractional lighting energy use for an ideal dimming system was then correlated to annual fractional lighting energy use for a fluorescent dimming system. Figure 4 shows a linear regression between an ideal dimming system and a fluorescent dimming system with a 10-100\% light output range for a $20-100 \%$ power range, $3 \%$ standby power when off and a setpoint illuminance level of 500 lux at desk height. Fractional lighting energy use was converted to energy for a fluorescent dimming system by multiplying the fractional value by the number of daytime work hours $(2600 \mathrm{~h})$ and the ASHRAE 90.12010 (American Society of Heating, Refrigerating and Air-Conditioning Engineers, Inc., 2010) maximum prescribed lighting power density (LPD) of $10.5 \mathrm{~W} / \mathrm{m}^{2}\left(0.98 \mathrm{~W} / \mathrm{ft}^{2}\right)$ for open plan offices for new construction, $14 \mathrm{~W} / \mathrm{m}^{2}\left(1.3 \mathrm{~W} / \mathrm{ft}^{2}\right)$ for retrofit construction (ASHRAE $\left.90.1-2001\right)$, and $8.1 \mathrm{~W} / \mathrm{m}^{2}(0.75$ $\mathrm{W} / \mathrm{ft}^{2}$ ) for new construction in California (Title-24 2013; California Energy Commission, 2012). 


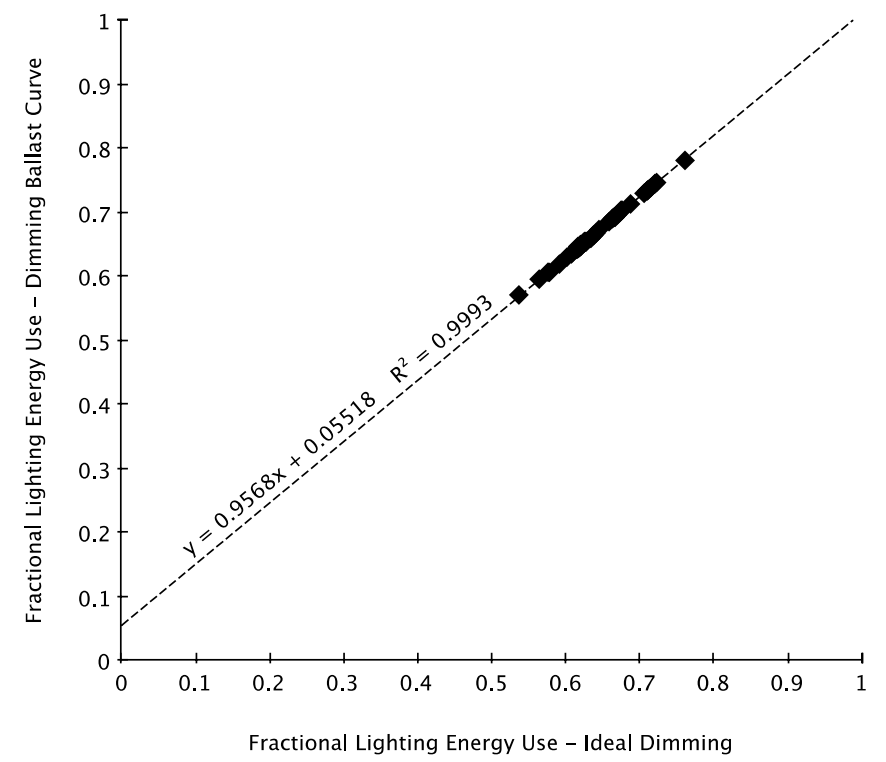

Fig. 4. Linear regression between fractional lighting energy use for an ideal dimming system and fluorescent dimming system.

\subsection{Discomfort glare}

The evaluation of discomfort glare was conducted using the daylight glare probability (DGP) and discomfort glare index (DGI), both of which were computed using the evalglare software tool (version 1.0; Wienold, 2012). The DGP index was derived from luminance data and subjective responses gathered in full-scale daylit spaces (Wienold and Christoffersen, 2006). The Cornell-Hopkinson DGI formula was derived from subjective responses to artificial lighting (Hopkinson and Bradley 1960). DGI has been found to have low correlation to actual end user response to glare from daylight. It is however included in this analysis as a conservative measure for glare analysis and to serve as a benchmark to prior studies.

For this analysis, the perimeter zone was illuminated solely with daylight so adaptation levels are expected to be lower than expected for views furthest from the window due to low overall light levels. Supplementary electric lighting would have raised adaptation levels and reduced frequency of discomfort glare, but inclusion of this additional potential glare source would have confounded the analysis and so was omitted in this study. The approach taken in this paper could produce a more conservative evaluation of discomfort glare for locations in the rear of the perimeter zone where discomfort glare is largely determined by luminance contrasts. Hirning et al. (2013) found that the DGP metric underestimated discomfort glare when the lighting conditions were dominated by contrast-based glare (low vertical illuminance) in a field study involving 63 office workers. If the DGP does underpredict discomfort glare when adaptation levels are low, then this assessment may be less conservative.

Hourly images with a resolution of $800 \times 800$ pixels were generated by Radiance for each of the nine view locations. Arbitrarily located glare sources with a solid angle greater than 0.002 steradians (st) were then identified in each image by evalglare using the default method: pixels with a luminance greater than the threshold luminance were identified as a potential glare source. The threshold luminance was defined as five times the average luminance (the recommended default value in evalglare) within the entire $180^{\circ}$ field of view or scene. Glare source pixels were then merged into one glare source given a search radius between pixels of 0.2 steradians. Non-glare source pixels were included with glare sources if they were surrounded by a glare source (i.e., smoothing option was used). Luminance peaks $\left(>50,000 \mathrm{~cd} / \mathrm{m}^{2}\right)$ were extracted as separate glare sources. 
To gain an understanding of when glare occurred as related to the prototypes' design, a glare/ no-glare hourly metric was defined based on the combined use of DGP and DGI values where for each hour (8:0018:00 LT, all weekdays of the year), if any of the nine views had a DGI value greater than 24 (threshold between "just acceptable and "just uncomfortable") or DGP value greater than 0.38 (average rating for "perceptible" glare) then the hour was determined to have glare. Threshold values were not selected to achieve equivalency between the DGP and DGI metrics since the fundamental definition of the two metrics differ.

Annual glare performance was classified by accounting for the frequency of glare within a threshold limit over a specified time period (Wienold, 2009):

- Class A or "best" class: $5 \%$ of the time must have an average DGP limit of 0.38 ("perceptible" glare) and $95 \%$ of the time period DGP must be less than or equal to 0.35 ("imperceptible" glare).

- Class B or "good" class: $5 \%$ of the time must have an average DGP limit of 0.42 ("disturbing" glare) and $95 \%$ of the time period DGP must be less than or equal to 0.40 ("perceptible" glare)

- Class C or "reasonable" class: $5 \%$ of the time must have an average DGP limit of 0.53 ("intolerable" glare) and $95 \%$ of the time period DGP must be less than or equal to 0.45 (“disturbing" glare).

These classes were calculated for the annual period defined by 8:00-18:00 LT, all weekdays of the year, including periods after sunset.

\section{Results}

\subsection{Characterization of the prismatic film}

Goniophotometric measurements of actual physical samples are generally more accurate than synthetic BSDF data generated using ray-tracing tools. Unfortunately, generating a full BSDF dataset through nonautomated measurements requires a significant investment of time. In prior work, the bidirectional scattering properties of the base materials used in complex fenestration systems (CFS), such as the fabric for roller shades or the painted metal finish on Venetian blinds, have been measured with a goniophotometer and these data were then used in a ray-tracing model to produce full BSDF datasets. This more practical approach was shown to produce data for solar heat gain analysis that were within acceptable limits of error (Andersen et al., 2005; Molina et al., 2015). Further validation work was conducted comparing synthetically-generated BSDF data using the genBSDF tool with measured data for flat mirrored blinds and a micro-perforated metal mesh shade (McNeil et al., 2013).

In this section, we describe how limited BSDF measurements of the prismatic film were made and how the full BSDF data set was generated using the genBSDF tool. A comparison between the measured and synthetic BSDF data was made. Comparisons between illuminance and field of view luminance were also made.

\subsubsection{Measured BSDF data}

A $25 \times 25 \mathrm{~cm}$ sample of the microstructured film adhered to the surface of a 3-mm thick clear glass substrate was provided by the manufacturer then measured using a goniophotometer. A total of eighteen angles of incidence were measured: a) nine for $\varphi_{i}=90^{\circ}$ (plane normal to the sample, vertical section) with $\theta_{\mathrm{i}}$ ranging from $0^{\circ}$ to $80^{\circ}$ at $10^{\circ}$ increments, and $\mathrm{b}$ ) nine for $\varphi_{\mathrm{i}}=45^{\circ}$ for the same set of $\theta_{\mathrm{i}}$ angles. The $\varphi_{\mathrm{i}}$ ("phi") angle represents the angle between the horizontal x-axis of the sample and the incoming ray projected onto the $x-y$ plane of the sample. The angle of incidence, $\theta_{i}$ ("theta"), is the angle between the 
incoming ray and the z-axis normal to the surface of the sample. Fig. 5 illustrates how these angles are defined for a CFS sample.
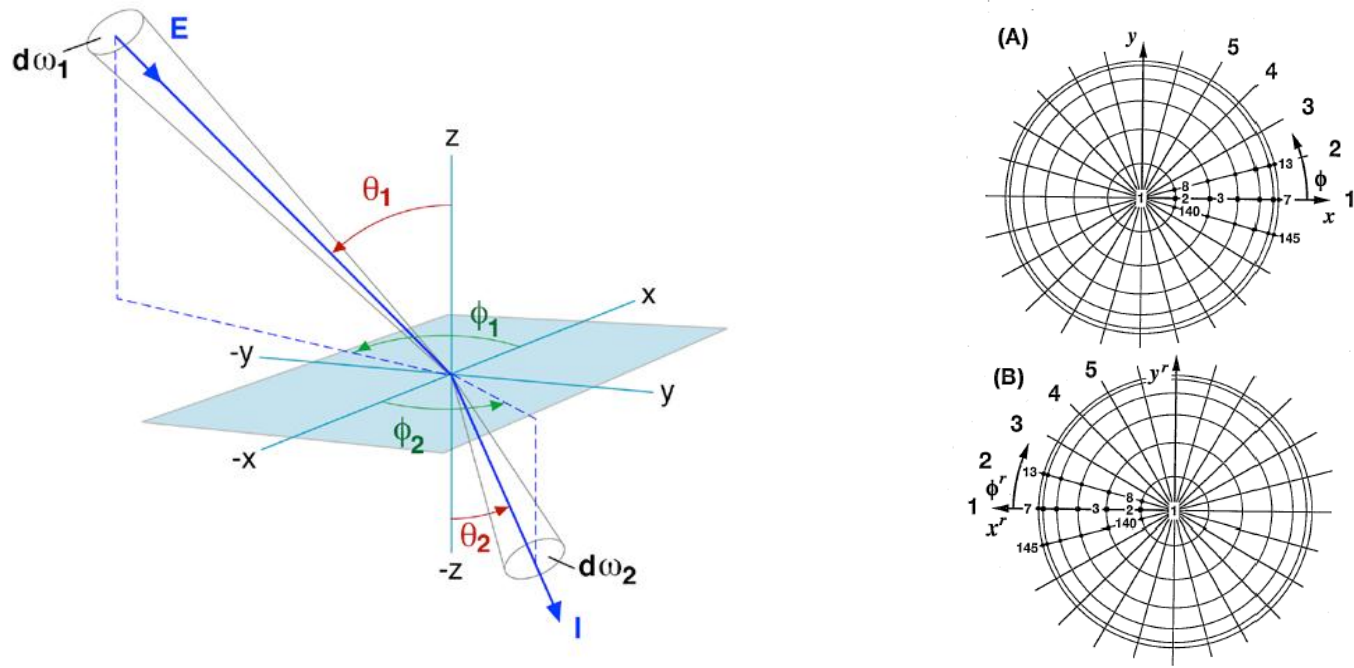

Fig. 5. General coordinate system for the definition of bidirectional properties (left). The incident polar coordinates are given by $\theta_{1}$ and $\varphi_{1}$ from differential space angle $d \omega_{1}$ that defines the source. Outgoing polar coordinates are given by the spherical coordinates $\theta_{1}$ and $\varphi_{1}$ for the outgoing differential space angle of $d \omega_{2}$. Definition of the Klems coordinate system used for representing discrete representation of bidirectional data (right). (A) Vector coordinates for incident and forward going radiation. The $\mathrm{z}$-axis is perpendicular to the plane and points toward the viewer. (B) Coordinates for backward-going radiation, a left-handed version of the system defined in (A).

Measurements were carried out with the the Lawrence Berkeley National Laboratory (LBNL) goniophotometer (Pab Advanced Technologies Ltd, PgII) using techniques developed by Apian-Bennewitz (2010; Grobe et al., 2010). A halogen tungsten lamp was used for the light source which illuminated 2.5$\mathrm{cm}$ diameter region of the sample (more than 10 periods of the microstructure) at normal incidence. Two wavelength bands were detected: the visible was obtained by using a vLambda filter over a Si-detector and the near infrared was obtained by using an unfiltered indium gallium arsenide (InGaAs) detector. Detector measurements were made at a uniform angular resolution of $1^{\circ}$ over the entire hemisphere with finer resolution sampling around the peaks.

Measured data for the visible spectrum are shown in Fig. 6 with a falsecolor log scale. The view shows the angular distribution and intensity of transmitted flux for the outgoing hemisphere with the outward surface normal (blue line) pointing to the left of the image and the top of the graph corresponding to the top of the vertically-positioned sample. Black regions within the circle indicate very low intensity values. The faint red line indicates the $\varphi_{\mathrm{i}}$ angle with the small yellow half-circle indicating the direction if specular transmission occurred and the red circle indicating the actual primary direction of peak transmission. The yellow line in the images showing data for $\varphi_{\mathrm{i}}=45^{\circ}$ indicates the horizontal line dividing the upper and lower halves of the hemisphere (note: the line is not broken if the peak is in the upper hemisphere).

$$
\varphi_{\mathrm{i}}=90^{\circ} \quad \varphi_{\mathrm{i}}=45^{\circ}
$$



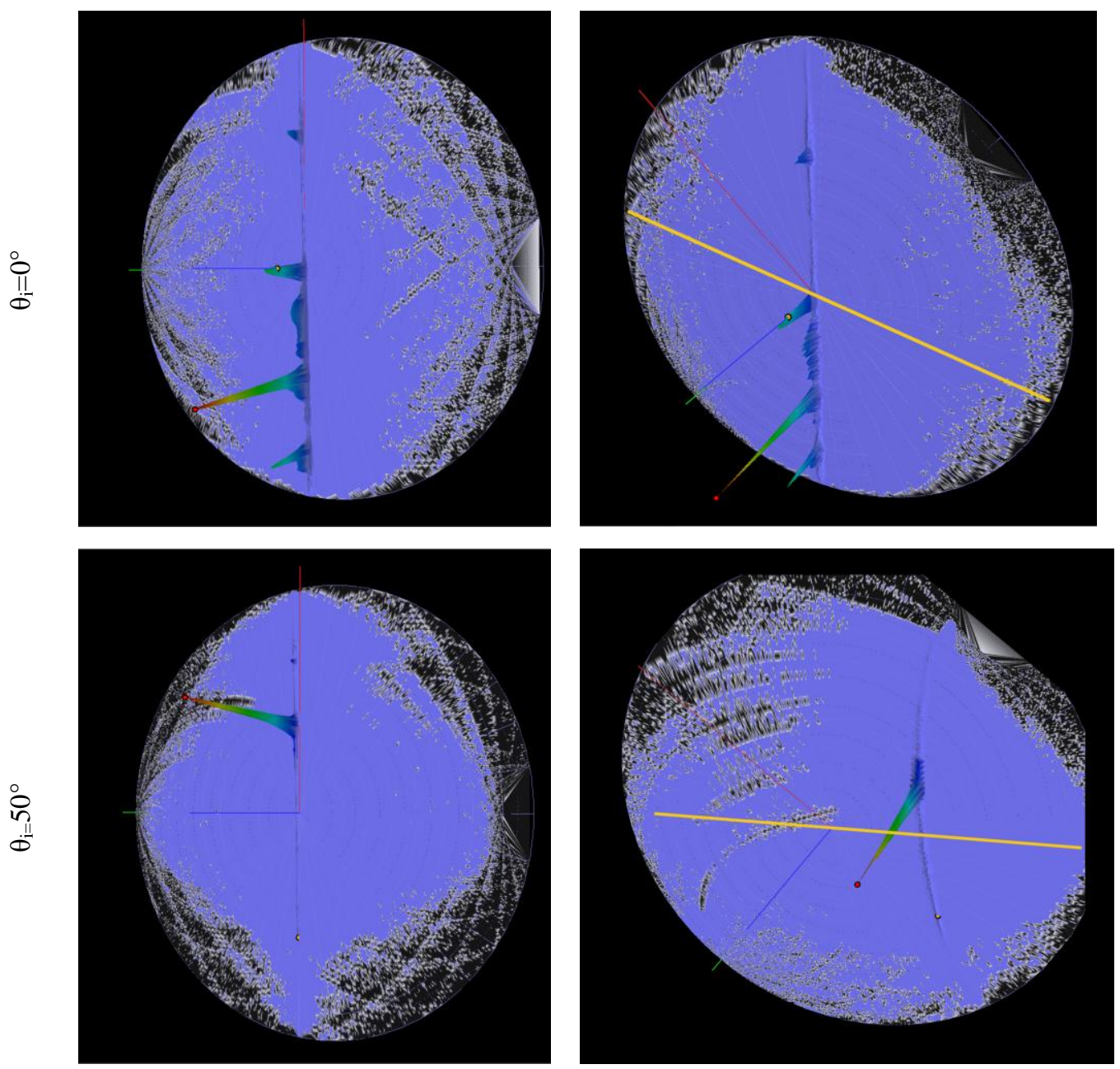

Fig. 6. Goniophotometric bidirectional transmittance distribution function (BTDF) data for visible light at an incident angle of $\theta_{\mathrm{i}}=0^{\circ}$ and $50^{\circ}$ with $\varphi_{\mathrm{i}}=90^{\circ}$ (left column) and $\varphi_{\mathrm{i}}=45^{\circ}$ (right column).

In Fig. 6 (left), the plot for normal incidence $\left(\theta_{\mathrm{i}}=0^{\circ}, \varphi_{\mathrm{i}}=90^{\circ}\right)$ shows a strong downward specularlytransmitting peak with additional smaller peaks also below the horizontal plane. By about $\theta_{\mathrm{i}}=30^{\circ}$, the outgoing light focuses into a single peak redirected above the horizontal plane. Light is striking the linear microprisms at angles where total internal reflection for this design is most efficient. After about $\theta_{\mathrm{i}}=60^{\circ}$, the outgoing light is still redirected upwards but multiple peaks begin to emerge.

When light is incident on the sample at an oblique angle, $\varphi_{\mathrm{i}}=45^{\circ}$ (Fig. 6 right), the same pattern occurs but a single strong peak occurs for $\theta_{\mathrm{i}}$ angles between $30^{\circ}$ to $80^{\circ}$; i.e., multiple peaks do not occur at the higher $\theta_{\mathrm{i}}$ angles. The light-redirecting effect still occurs, but not quite as efficiently as for the $\varphi_{\mathrm{i}}=90^{\circ}$ incident angle: light is striking the linear face of the microprisms at an off-normal angle. Notice also the vertical arc in these figures, which indicate a continuous region of low-level transmission. This bright arc is noticeable when a large-area sample of the film is viewed at some angles on a sunny day (Fig. 7). 


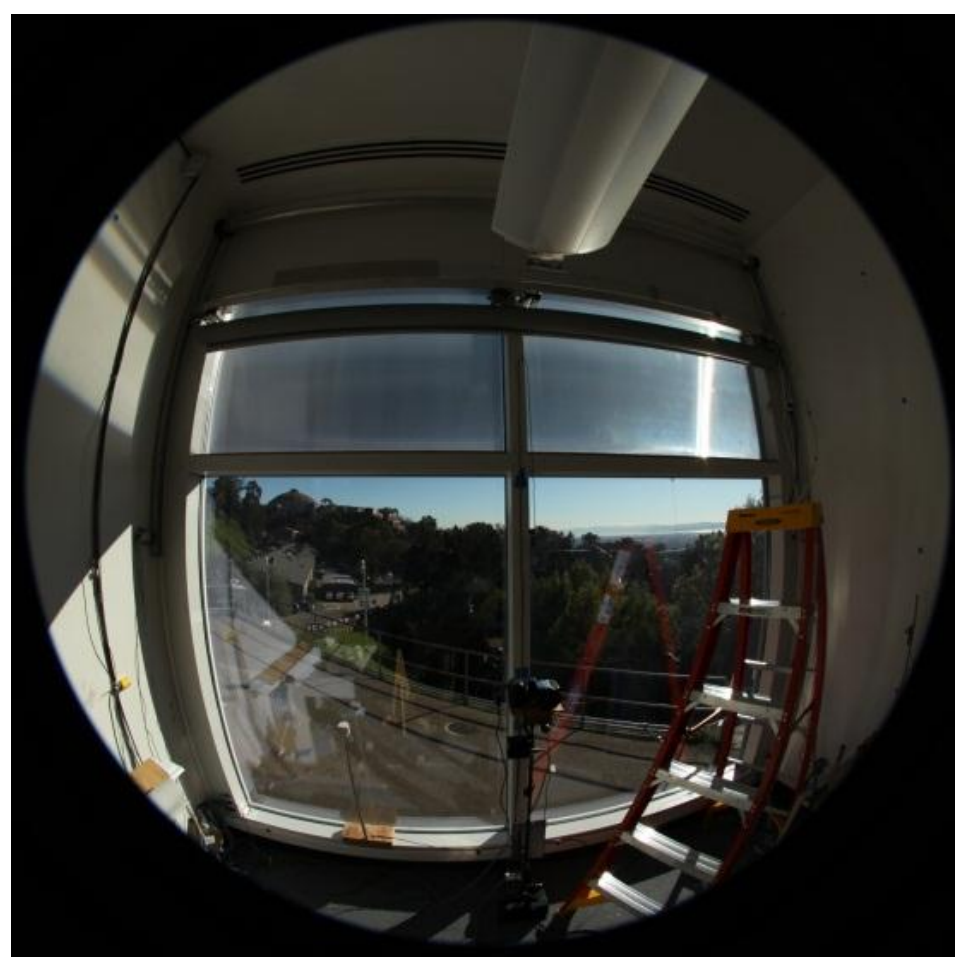

Fig. 7. Interior view of the film installed in the two upper clerestory windows. The bright arc of sunlight being redirected to the viewer is visible close to the right-most edge of the right window.

The outgoing angle of the transmitted peak with the greatest magnitude was determined for each incident angle then plotted in a summary graph in Fig. 8. For $\varphi_{\mathrm{i}}$ angles between $45^{\circ}$ and $135^{\circ}$ (since the system is axially symmetric) corresponding to mid-day hours for a south-facing facade, this microstructured film was able to achieve a low outgoing angle of redirection when the sun or incoming light was within $\theta_{\mathrm{i}}$ incident angles between about $18-35^{\circ}$. An outgoing angle of about $3-5^{\circ}$ enables flux to penetrate further from the window wall to targeted depths of about 9-12 m (30-40 ft). Negative outgoing angles will cause glare.

The front visible reflectance of the sample is shown in Fig. 9. For the primary incident angles where the system was found to be most efficient at redirection, the front reflectance was found to be low, between 0.10 and 0.15 for $\theta_{\mathrm{i}}$ incident angles between $10^{\circ}$ to $60^{\circ}$. The effect is dominated by the glass substrate reflectance rather than dependent on the film properties. There were no significant indications that the azimuth $\left(\varphi_{\mathrm{i}}\right)$ influences total reflectance. 


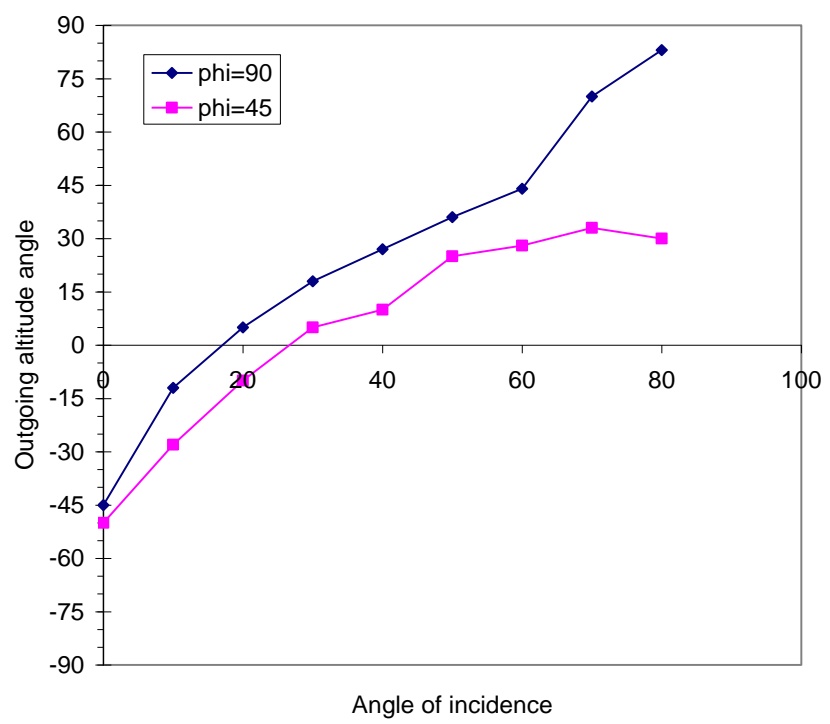

Fig. 8. Outgoing angle of the largest recorded BTDF value versus $\theta_{i}$ angle of incidence for $\varphi_{i}=90^{\circ}$ and $45^{\circ}$.

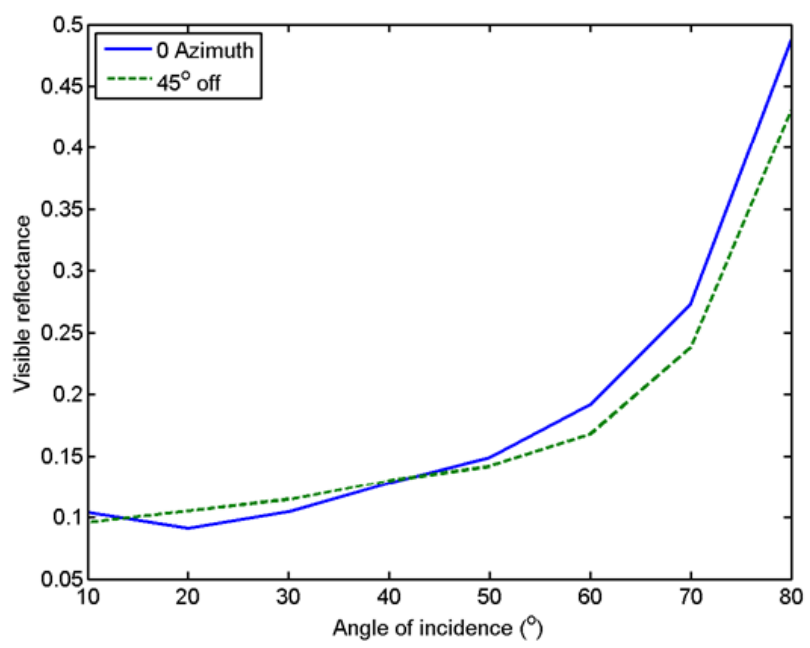

Fig. 9. Direct-hemispherical front visible reflectance integrated from measured BRDFs versus $\theta_{\mathrm{i}}$ angle of incidence for $\varphi_{\mathrm{i}}=0^{\circ}$ and $45^{\circ}$.

\subsubsection{Synthetic BSDF data}

The original design was not expected to match the fabricated prototype due to defects introduced during manufacturing. Exact causes for variations in profile geometry are unknown. The surface relief grating is created by pressing a mold into a resin at high throughput in a roll-to-roll process. Small deviations from design may occur when the die is withdrawn or during the curing process when shrinkage may occur. We attempted to capture the variation in the prismatic film's geometry with modeling using geometric inputs from various sources:

a) the original formulated design by the manufacturer (drawing of the profile) and

b) two drawn profiles of the fabricated structure taken from scans conducted by the manufacturer using an electron microscope. 
The profiles generated using method (b) illustrated that there were slight variations in the fabricated profile. Separate BSDF datasets were generated using the Radiance genBSDF tool for the original design and for the two drawn profiles (b). A fourth BSDF dataset ("genBSDF average") was generated by averaging the intensities from each of the three separate synthetic datasets for each outgoing patch and incident angle. This fourth dataset was used for the evaluations described in the following sections and in Section 3.2.

\subsubsection{Comparison of synthetic BSDF data to goniophotometer measurements}

A comparison of the direct hemispherical transmittance between the genBSDF average dataset and the measured goniophotometric dataset for the $\mathrm{P} 1$ prismatic film mounted on $3 \mathrm{~mm}$ clear glass shows good agreement with the exception of $\theta$ greater than $60^{\circ}$ (Fig. 10). The discrepancy at these higher outgoing angles could be explained by experimental noise; the noise gets amplified at the highest angles since the measured signal is divided by the cosine of the outgoing angle. The measured signal in the goniophotometer is proportional to $\mathrm{BSDF}^{*} \cos \theta$ so when calculating the BSDF, the noise is amplified by a very large factor for $\theta$ values near $90^{\circ}$.

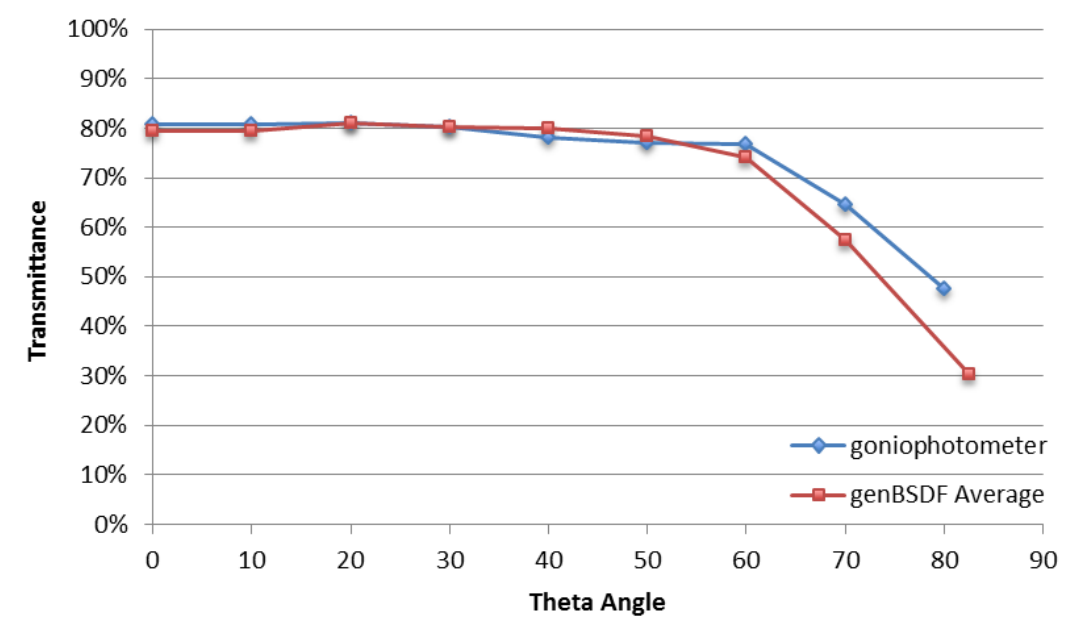

Fig. 10. Direct-hemispherical transmittance as a function of incident angle $\left(\theta_{\mathrm{i}}=0-82.5^{\circ}\right)$ in the plane normal to the prismatic film $\left(\varphi_{\mathrm{i}}=90^{\circ}\right)$. Measured goniophotometric and synthetic genBSDF bidirectional transmittance distribution data were computed using the full Klems basis for the various incident angles.

The measured and averaged genBSDF synthetic data computed using the Klems basis are shown for varying incident angles $\left(\theta_{\mathrm{i}}=0-82.5^{\circ}\right)$ in the plane normal to the prismatic film $\left(\varphi_{\mathrm{i}}=90^{\circ}\right)$ in Fig. 11 . If the transmitted flux is redirected upward, then the flux will occur in the positive outgoing patch angles. Negative patch angles capture downward transmitted flux. The peak transmission was found to occur for the most part in the same outgoing patch for incident angles between $20-70^{\circ}$. At normal and very oblique angles of incidence, multiple outgoing peaks emerged and the peak energy was spread between adjacent patches so agreement between the two datasets was less. The intensity of the peak transmitted energy of the genBSDF dataset was also found to be less than the measured data for most incident angles even though the synthetic data predicted less scatter. 

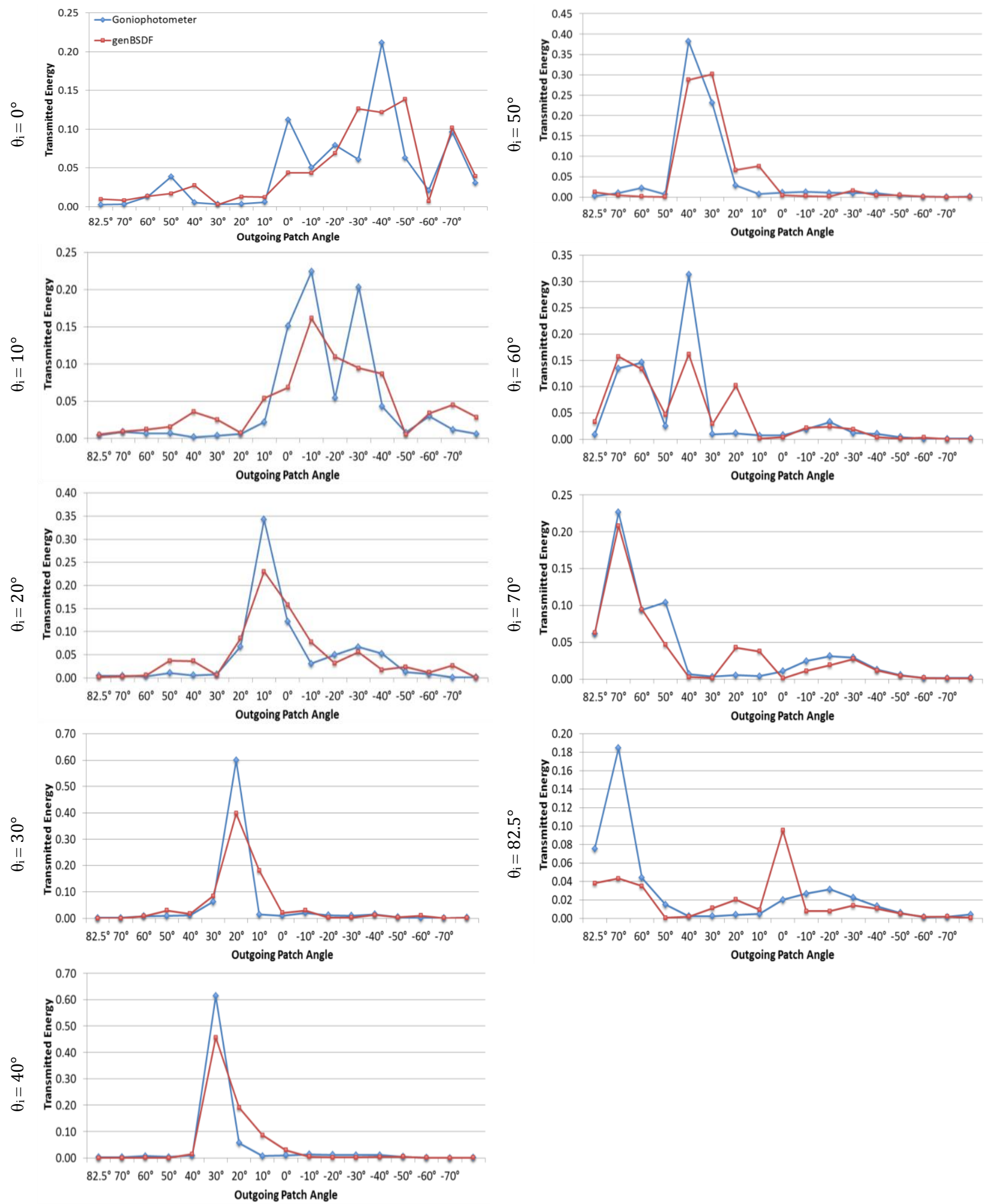

Fig. 11. Measured goniophotometric and synthetic genBSDF bidirectional transmittance distribution data computed using the full Klems basis are shown for varying incident angles $\left(\theta_{\mathrm{i}}=0-82.5^{\circ}\right)$ in the plane normal to the prismatic film $\left(\varphi_{\mathrm{i}}=90^{\circ}\right)$. Outgoing patch angles are given for $\theta_{\mathrm{e}}=82.5^{\circ}$ (upwards to the ceiling plane to $-82.5^{\circ}$ (downwards to floor). The synthetic data are given for the average BSDF dataset. Data are given for the P1 film on a $3 \mathrm{~mm}$ clear glass substrate. 


\subsubsection{Comparison of illuminance and luminance from measured versus synthetic BSDF data}

To determine the significance of the differences between the measured and synthetic averaged BSDF dataset, average workplane illuminance levels in the open plan office zones were computed, where the sun and sky intensity was assigned to a single incident direction $\left(\theta_{\mathrm{i}}=20^{\circ}, 30^{\circ}, 40^{\circ}, 50^{\circ}, 60^{\circ}\right.$ and $\left.70^{\circ}, \varphi_{\mathrm{i}}=90^{\circ}\right)$. These data are shown in Table 4. The relative difference in average illuminance between genBSDF and goniophotometer BSDFs is low for the first two zones. In the first two zones the angular difference in the peak transmission has a muted effect on illuminance, overall transmission is much more critical. For the third and fourth zones, the difference in angular direction of the peak has much greater effect, as is evidenced by relative differences ranging from $-44 \%$ to $46 \%$. These large percentage differences result from minor differences in the BSDF data, whether or not the full intensity of a peak is contained in one patch or spread over several. Such difference can be considered local and random, and as such they will average out as the other angles of incidence over the incoming hemisphere are considered at once, similar to the total hemispherical data where all outgoing angles are integrated to one value in Fig. 10.

Table 4

Average workplane illuminance (lux) for a single incident direction. Data are given for the P1 film on a 3 $\mathrm{mm}$ clear glass substrate.

\begin{tabular}{|c|c|c|c|c|c|}
\hline \multirow[t]{2}{*}{$\varphi_{\mathrm{i}}=90^{\circ}$} & Zone (m) & $0-3.0$ & $3.0-6.1$ & $6.1-9.2$ & $9.2-12.2$ \\
\hline & Zone (ft) & $0-10$ & $10-20$ & $20-30$ & $30-40$ \\
\hline \multirow[t]{4}{*}{$\Theta i=20^{\circ}$} & goniophotometer & 4250 & 1858 & 546 & 349 \\
\hline & genBSDF & 3900 & 1569 & 672 & 455 \\
\hline & absolute difference & -350 & -289 & 127 & 106 \\
\hline & relative difference & $-8 \%$ & $-16 \%$ & $23 \%$ & $30 \%$ \\
\hline \multirow[t]{4}{*}{$\Theta i=30^{\circ}$} & goniophotometer & 5363 & 1332 & 295 & 117 \\
\hline & genBSDF & 5068 & 1571 & 432 & 166 \\
\hline & absolute difference & -295 & 239 & 138 & 49 \\
\hline & relative difference & $-5 \%$ & $18 \%$ & $47 \%$ & $42 \%$ \\
\hline \multirow[t]{4}{*}{$\Theta i=40^{\circ}$} & goniophotometer & 4307 & 899 & 208 & 81 \\
\hline & genBSDF & 4235 & 1023 & 240 & 118 \\
\hline & absolute difference & -71 & 124 & 32 & 37 \\
\hline & relative difference & $-2 \%$ & $14 \%$ & $15 \%$ & $46 \%$ \\
\hline \multirow[t]{4}{*}{$\Theta i=50^{\circ}$} & goniophotometer & 3723 & 692 & 196 & 79 \\
\hline & genBSDF & 3919 & 798 & 188 & 60 \\
\hline & absolute difference & 196 & 106 & -7 & -19 \\
\hline & relative difference & $5 \%$ & $15 \%$ & $-4 \%$ & $-24 \%$ \\
\hline \multirow[t]{4}{*}{$\Theta i=60^{\circ}$} & goniophotometer & 2523 & 585 & 147 & 60 \\
\hline & genBSDF & 2443 & 554 & 137 & 51 \\
\hline & absolute difference & -80 & -30 & -10 & -8 \\
\hline & relative difference & $-3 \%$ & $-5 \%$ & $-7 \%$ & $-14 \%$ \\
\hline \multirow[t]{7}{*}{$\Theta i=70^{\circ}$} & goniophotometer & 1534 & 380 & 96 & 44 \\
\hline & genBSDF & 1396 & 331 & 69 & 24 \\
\hline & absolute difference & -137 & -49 & -27 & -19 \\
\hline & relative difference & $-9 \%$ & $-13 \%$ & $-28 \%$ & $-44 \%$ \\
\hline & Mean absolute difference & -122 & 17 & 42 & 24 \\
\hline & Mean relative difference & $4 \%$ & $2 \%$ & $8 \%$ & $6 \%$ \\
\hline & RMS relative difference & $6 \%$ & $14 \%$ & $25 \%$ & $35 \%$ \\
\hline
\end{tabular}

Using a similar method, images of the open plan office were generated using the measured or synthetic averaged BSDF datasets, where the sun and sky intensity was assigned to a single incident direction $\left(\theta_{\mathrm{i}}=\right.$ $20^{\circ}$ or $50^{\circ}, \varphi_{\mathrm{i}}=90^{\circ}$ ). The relative difference images in Fig. 12 (righthand column) show that the synthetic genBSDF dataset produced significantly greater ceiling luminance than the measured BSDF dataset for 
most incident angles. These images also show little difference in workplane illuminance aside from the portion of the desk close to the partition parallel to the window, which is predominately illuminated by daylight reflected from deeper regions of the ceiling.

Modeled performance is likely to be improved if a greater number of measured profiles of the manufactured prismatic film were modeled and if resolution of the BSDF basis was increased (e.g., two or four times the full $145 \times 145$ Klems basis). Use of variable resolution BSDF datasets, which provide highlyresolved data (i.e., smaller solid angles per patch) in areas where peak transmission occurs (Ward et al. 2012) would also improve modeled performance.

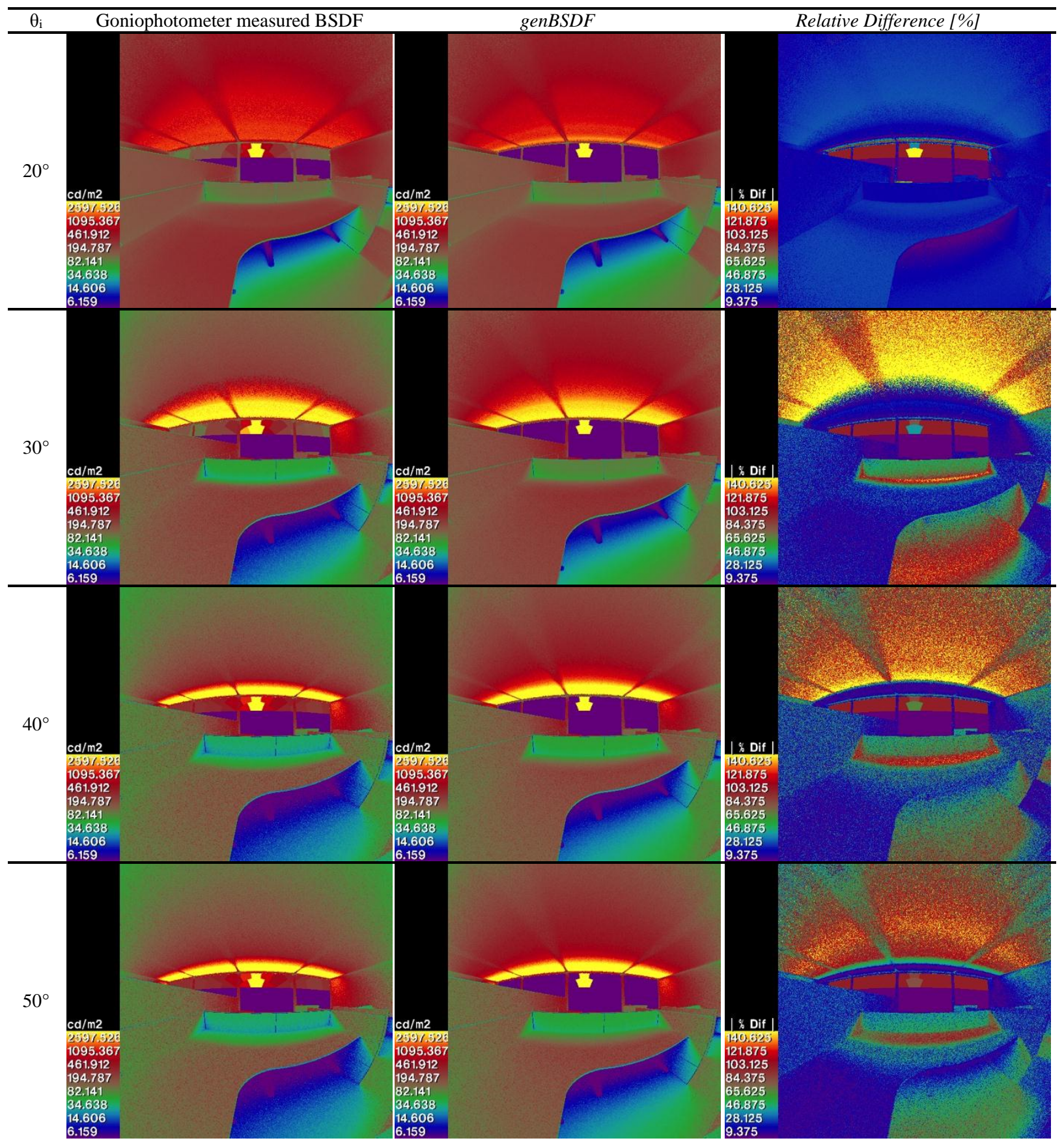




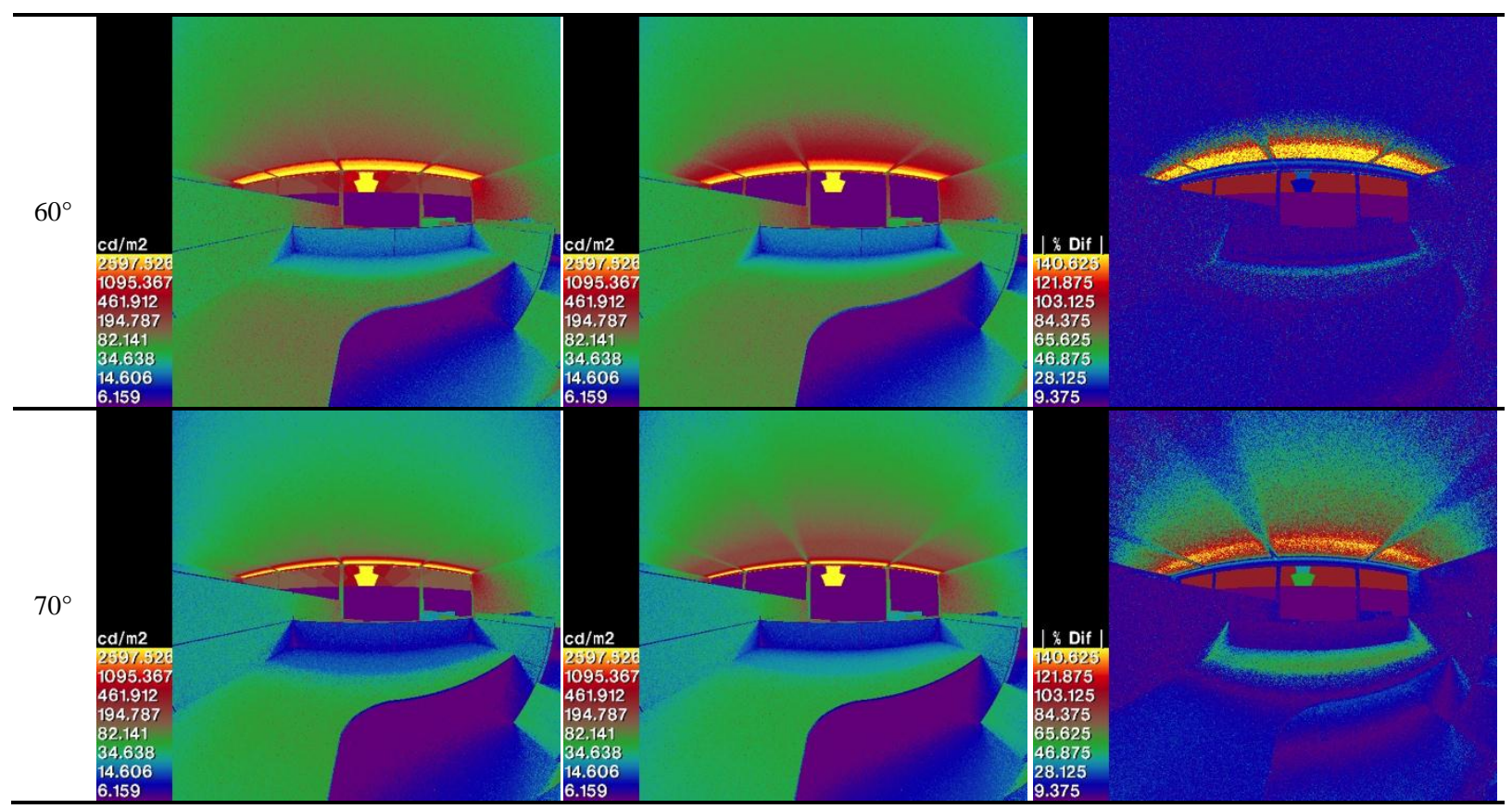

Fig. 12. Renderings of an open plan office zone looking toward windows with the P1 film applied to a $3 \mathrm{~mm}$ clear glass substrate. The left column of images were generated using goniophotometric BSDF data for incident angles of $20^{\circ}$ and $50^{\circ}$ while the center column of images were generated using genBSDF data. The falsecolor linear scale runs from $0-2598 \mathrm{~cd} / \mathrm{m}^{2}$, where values greater than $2598 \mathrm{~cd} / \mathrm{m}^{2}$ are also shown in yellow. The right column contains the absolute value of relative error.

\subsection{Annual performance of the daylight-redirecting systems}

\subsubsection{Annual lighting energy use and peak demand}

Radiance parametric simulations were run for the reference, P1, and P2 window conditions for south- and east-facing perimeter zones in four climates: Chicago, Houston, Sacramento, and Burbank (Table 5).

Results are summarized for varying depths of the perimeter zone in Table 6. The P1 system produced the greatest lighting energy savings while the reference Venetian blind produced the least. The P2 system, for example, produced 22-23\% greater savings in fractional lighting energy use compared to the Venetian blind system with the same lighting control system in a $40 \mathrm{ft}$ deep south zone across the four climates. For eastfacing zones, the P2 system was slightly less effective, producing 19-21\% savings compared to the reference blind.

Table 5

Summary data for modeled climates.

\begin{tabular}{lclll}
\hline City & Latitude $\left({ }^{\circ} \mathrm{N}\right)$ & $\begin{array}{l}\text { Percent of } \\
\text { Annual Average } \\
\text { Possible } \\
\text { Sunshine* }\end{array}$ & $\begin{array}{l}\text { Annual } \\
\text { Cooling } \\
\text { Degree Days } \\
\left(65^{\circ} \mathrm{F}\right)\end{array}$ & $\begin{array}{l}\text { Annual Heating } \\
\text { Degree Days } \\
\left(65^{\circ} \mathrm{F}\right)\end{array}$ \\
\hline Chicago, Illinois & $41.85^{\circ}$ & $54 \%$ & 468 & 3506 \\
Houston, Texas & $29.76^{\circ}$ & $59 \%$ & 1667 & 786 \\
Sacramento, California & $38.58^{\circ}$ & $78 \%$ & 673 & 1411 \\
Burbank, California & $34.18^{\circ}$ & $73 \%$ & 826 & 721 \\
\hline * http://www1.ncdc.noaa.gov/pub/data/ccd-data/pctposrank.txt (accessed April 15, 2016)
\end{tabular}

Annual source lighting energy use for three levels of lighting power density is also given in Table 6, where the site-to-source electricity conversion factor was 3.3. Compared to a non-daylit perimeter zone with a total annual source lighting energy use of $120 \mathrm{kWh} / \mathrm{m}^{2}-\mathrm{yr}\left(11.15 \mathrm{kWh} / \mathrm{ft}^{2}-\mathrm{yr}\right)$, energy savings for the P2 system in a $12.2 \mathrm{~m}$ (40 ft) deep dimming zone were $46.8-51.4 \mathrm{kWh} / \mathrm{m}^{2}-\mathrm{yr}\left(4.35-4.78 \mathrm{kWh} / \mathrm{ft}^{2}-\mathrm{yr}\right), 39-43 \%$ 
for the south-facing perimeter zone across all climates with an installed lighting power density (LPD) of 14 $\mathrm{W} / \mathrm{m}^{2}\left(1.3 \mathrm{~W} / \mathrm{ft}^{2}\right)$. With an installed LPD of $8.1 \mathrm{~W} / \mathrm{m}^{2}\left(0.75 \mathrm{~W} / \mathrm{ft}^{2}\right)$ and annual energy use of $69.3 \mathrm{kWh} / \mathrm{m}^{2}-$ yr $\left(6.44 \mathrm{kWh} / \mathrm{ft}^{2}-\mathrm{yr}\right)$, savings were $27.0-29.7 \mathrm{kWh} / \mathrm{m}^{2}$-yr $\left(2.51-2.76 \mathrm{kWh} / \mathrm{ft}^{2}-\mathrm{yr}\right)$ or $39-43 \%$.

Compared to a south-facing perimeter zone with Venetian blinds and daylighting controls, total annual source lighting energy use savings for the P2 system across the $12.2 \mathrm{~m}$ (40 ft) deep dimming zone were $18.4-19.5 \mathrm{kWh} / \mathrm{m}^{2}-\mathrm{yr}\left(1.71-1.81 \mathrm{kWh} / \mathrm{ft}^{2}-\mathrm{yr}\right)$ or $20-22 \%$ across all climates with an installed LPD of 14 $\mathrm{W} / \mathrm{m}^{2}\left(1.3 \mathrm{~W} / \mathrm{ft}^{2}\right)$. With an installed LPD of $8.1 \mathrm{~W} / \mathrm{m}^{2}\left(0.75 \mathrm{~W} / \mathrm{ft}^{2}\right)$, savings were $10.7-11.3 \mathrm{kWh} / \mathrm{m}^{2}-\mathrm{yr}$ $\left(0.99-1.05 \mathrm{kWh} / \mathrm{ft}^{2}-\mathrm{yr}\right)$ or $20-22 \%$.

Table 6

Fractional lighting energy use (FLE) and annual source lighting energy use $\left(\mathrm{kWh} / \mathrm{ft}^{2}-\mathrm{yr}\right)$ for three levels of lighting power density.

\begin{tabular}{|c|c|c|c|c|c|c|c|c|c|c|c|}
\hline & & & \multicolumn{3}{|c|}{$0-20 \mathrm{ft}$ zone } & \multicolumn{3}{|c|}{$0-30 \mathrm{ft}$ zone } & \multicolumn{3}{|c|}{$0-40 \mathrm{ft}$ zone } \\
\hline & & & VB & $\mathrm{P} 1$ & $\mathrm{P} 2$ & VB & P1 & P2 & VB & $\mathrm{P} 1$ & P2 \\
\hline \multirow{10}{*}{ 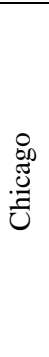 } & & FLE & 0.55 & 0.29 & 0.32 & 0.68 & 0.45 & 0.48 & 0.75 & 0.56 & 0.58 \\
\hline & & savings & & $48 \%$ & $42 \%$ & & $33 \%$ & $29 \%$ & & $25 \%$ & $22 \%$ \\
\hline & $\mathrm{S}$ & $1.3 \mathrm{~W} / \mathrm{ft}^{2}$ & 6.49 & 3.71 & 4.03 & 7.87 & 5.42 & 5.74 & 8.62 & 6.59 & 6.81 \\
\hline & & $0.98 \mathrm{~W} / \mathrm{ft}^{2}$ & 4.89 & 2.80 & 3.04 & 5.93 & 4.08 & 4.33 & 6.50 & 4.97 & 5.13 \\
\hline & & $0.75 \mathrm{~W} / \mathrm{ft}^{2}$ & 3.74 & 2.14 & 2.33 & 4.54 & 3.13 & 3.31 & 4.97 & 3.80 & 3.93 \\
\hline & & FLE & 0.64 & 0.37 & 0.41 & 0.74 & 0.53 & 0.56 & 0.8 & 0.63 & 0.65 \\
\hline & & Savings & & $42 \%$ & $35 \%$ & & $29 \%$ & $24 \%$ & & $22 \%$ & $19 \%$ \\
\hline & E & $1.3 \mathrm{~W} / \mathrm{ft}^{2}$ & 7.45 & 4.56 & 4.99 & 8.51 & 6.27 & 6.59 & 9.15 & 7.34 & 7.55 \\
\hline & & $0.98 \mathrm{~W} / \mathrm{ft}^{2}$ & 5.61 & 3.44 & 3.76 & 6.42 & 4.73 & 4.97 & 6.90 & 5.53 & 5.69 \\
\hline & & $0.75 \mathrm{~W} / \mathrm{ft}^{2}$ & 4.30 & 2.63 & 2.88 & 4.91 & 3.62 & 3.80 & 5.28 & 4.23 & 4.36 \\
\hline \multirow{10}{*}{$\begin{array}{l}0 \\
0 \\
0 \\
0 \\
\underline{I}\end{array}$} & & FLE & 0.54 & 0.27 & 0.3 & 0.67 & 0.45 & 0.47 & 0.74 & 0.56 & 0.58 \\
\hline & & Savings & & $51 \%$ & $45 \%$ & & $34 \%$ & $30 \%$ & & $25 \%$ & $22 \%$ \\
\hline & $\mathrm{S}$ & $1.3 \mathrm{~W} / \mathrm{ft}^{2}$ & 6.38 & 3.50 & 3.82 & 7.77 & 5.42 & 5.63 & 8.51 & 6.59 & 6.81 \\
\hline & & $0.98 \mathrm{~W} / \mathrm{ft}^{2}$ & 4.81 & 2.64 & 2.88 & 5.85 & 4.08 & 4.25 & 6.42 & 4.97 & 5.13 \\
\hline & & $0.75 \mathrm{~W} / \mathrm{ft}^{2}$ & 3.68 & 2.02 & 2.20 & 4.48 & 3.13 & 3.25 & 4.91 & 3.80 & 3.93 \\
\hline & & FLE & 0.59 & 0.31 & 0.35 & 0.71 & 0.48 & 0.51 & 0.77 & 0.58 & 0.61 \\
\hline & & Savings & & $48 \%$ & $41 \%$ & & $32 \%$ & $28 \%$ & & $24 \%$ & $21 \%$ \\
\hline & E & $1.3 \mathrm{~W} / \mathrm{ft}^{2}$ & 6.91 & 3.92 & 4.35 & 8.19 & 5.74 & 6.06 & 8.83 & 6.81 & 7.13 \\
\hline & & $0.98 \mathrm{~W} / \mathrm{ft}^{2}$ & 5.21 & 2.96 & 3.28 & 6.18 & 4.33 & 4.57 & 6.66 & 5.13 & 5.37 \\
\hline & & $0.75 \mathrm{~W} / \mathrm{ft}^{2}$ & 3.99 & 2.26 & 2.51 & 4.73 & 3.31 & 3.50 & 5.10 & 3.93 & 4.11 \\
\hline \multirow{10}{*}{ 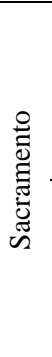 } & & FLE & 0.49 & 0.24 & 0.28 & 0.63 & 0.41 & 0.44 & 0.71 & 0.53 & 0.55 \\
\hline & & Savings & & $50 \%$ & $44 \%$ & & $34 \%$ & $30 \%$ & & $26 \%$ & $23 \%$ \\
\hline & $\mathrm{S}$ & $1.3 \mathrm{~W} / \mathrm{ft}^{2}$ & 5.84 & 3.18 & 3.60 & 7.34 & 4.99 & 5.31 & 8.19 & 6.27 & 6.49 \\
\hline & & $0.98 \mathrm{~W} / \mathrm{ft}^{2}$ & 4.41 & 2.39 & 2.72 & 5.53 & 3.76 & 4.00 & 6.18 & 4.73 & 4.89 \\
\hline & & $0.75 \mathrm{~W} / \mathrm{ft}^{2}$ & 3.37 & 1.83 & 2.08 & 4.23 & 2.88 & 3.06 & 4.73 & 3.62 & 3.74 \\
\hline & & FLE & 0.57 & 0.32 & 0.36 & 0.69 & 0.48 & 0.51 & 0.76 & 0.58 & 0.61 \\
\hline & & Savings & & $43 \%$ & $37 \%$ & & $31 \%$ & $26 \%$ & & $23 \%$ & $20 \%$ \\
\hline & E & $1.3 \mathrm{~W} / \mathrm{ft}^{2}$ & 6.70 & 4.03 & 4.46 & 7.98 & 5.74 & 6.06 & 8.73 & 6.81 & 7.13 \\
\hline & & $0.98 \mathrm{~W} / \mathrm{ft}^{2}$ & 5.05 & 3.04 & 3.36 & 6.02 & 4.33 & 4.57 & 6.58 & 5.13 & 5.37 \\
\hline & & $0.75 \mathrm{~W} / \mathrm{ft}^{2}$ & 3.86 & 2.33 & 2.57 & 4.60 & 3.31 & 3.50 & 5.03 & 3.93 & 4.11 \\
\hline \multirow{10}{*}{ 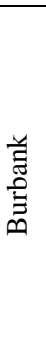 } & & FLE & 0.48 & 0.24 & 0.27 & 0.62 & 0.41 & 0.43 & 0.71 & 0.52 & 0.54 \\
\hline & & Savings & & $51 \%$ & $45 \%$ & & $35 \%$ & $31 \%$ & & $26 \%$ & $23 \%$ \\
\hline & $\mathrm{S}$ & $1.3 \mathrm{~W} / \mathrm{ft}^{2}$ & 5.74 & 3.18 & 3.50 & 7.23 & 4.99 & 5.20 & 8.19 & 6.16 & 6.38 \\
\hline & & $0.98 \mathrm{~W} / \mathrm{ft}^{2}$ & 4.33 & 2.39 & 2.64 & 5.45 & 3.76 & 3.92 & 6.18 & 4.65 & 4.81 \\
\hline & & $0.75 \mathrm{~W} / \mathrm{ft}^{2}$ & 3.31 & 1.83 & 2.02 & 4.17 & 2.88 & 3.00 & 4.73 & 3.56 & 3.68 \\
\hline & & FLE & 0.57 & 0.31 & 0.34 & 0.69 & 0.47 & 0.5 & 0.76 & 0.58 & 0.6 \\
\hline & & Savings & & $45 \%$ & $39 \%$ & & $31 \%$ & $27 \%$ & & $23 \%$ & $21 \%$ \\
\hline & E & $1.3 \mathrm{~W} / \mathrm{ft}^{2}$ & 6.70 & 3.92 & 4.24 & 7.98 & 5.63 & 5.95 & 8.73 & 6.81 & 7.02 \\
\hline & & $0.98 \mathrm{~W} / \mathrm{ft}^{2}$ & 5.05 & 2.96 & 3.20 & 6.02 & 4.25 & 4.49 & 6.58 & 5.13 & 5.29 \\
\hline & & $0.75 \mathrm{~W} / \mathrm{ft}^{2}$ & 3.86 & 2.26 & 2.45 & 4.60 & 3.25 & 3.43 & 5.03 & 3.93 & 4.05 \\
\hline
\end{tabular}

Temporal plots of fractional lighting energy use are given in Fig. 13-15 for the south facing perimeter zone in Sacramento. In Section 3.1, the goniophotometric data indicated that the outgoing angles of redirection were more optimal between the equinox and winter solstice. This is supported by the temporal plots where 
the most significant reductions in lighting occur during the core daytime hours (9:00-15:00) from March to September, influencing zones 3 and 4 or 6.1-12.2 m (20-40 ft) from the window.

Building owners generally find that installing dimmable lighting controls in the first one to two times the head height of the window (9-18 ft) is economical. If the installed cost of the daylighting film to the consumer is assumed to be $\$ 20 / \mathrm{ft}^{2}$-window (based on mature market estimates from industry), the simple payback is 2.2 to 3.3 years for a $0-20 \mathrm{ft}$ and $0-30 \mathrm{ft}$ dimming zone, respectively, assuming an LPD of 1.3 $\mathrm{W} / \mathrm{ft}^{2}$. With an LPD of $0.75 \mathrm{~W} / \mathrm{ft}^{2}$, the payback lengthens to 3.8 to 6.3 years for the $0-20 \mathrm{ft}$ and $0-30 \mathrm{ft}$ dimming zone, respectively. If the added installed cost of the daylighting controls at $\$ 2 / \mathrm{ft}^{2}-\mathrm{floor}$ is included in the total, then the simple payback increases to 4.0 to 7.5 years for the LPD of $1.3 \mathrm{~W} / \mathrm{ft}^{2}$ and 7.0 to 14.2 years for the LPD of $0.75 \mathrm{~W} / \mathrm{ft}^{2}$, respectively for the two zone depths. This analysis assumes a utility rate of $\$ 0.20 \mathrm{US} / \mathrm{kWh}$, product life of 30 years, and discount rate of $6 \%$. The utility rate is an average flat rate equivalent for metropolitan areas that impose time-of-use demand charges.
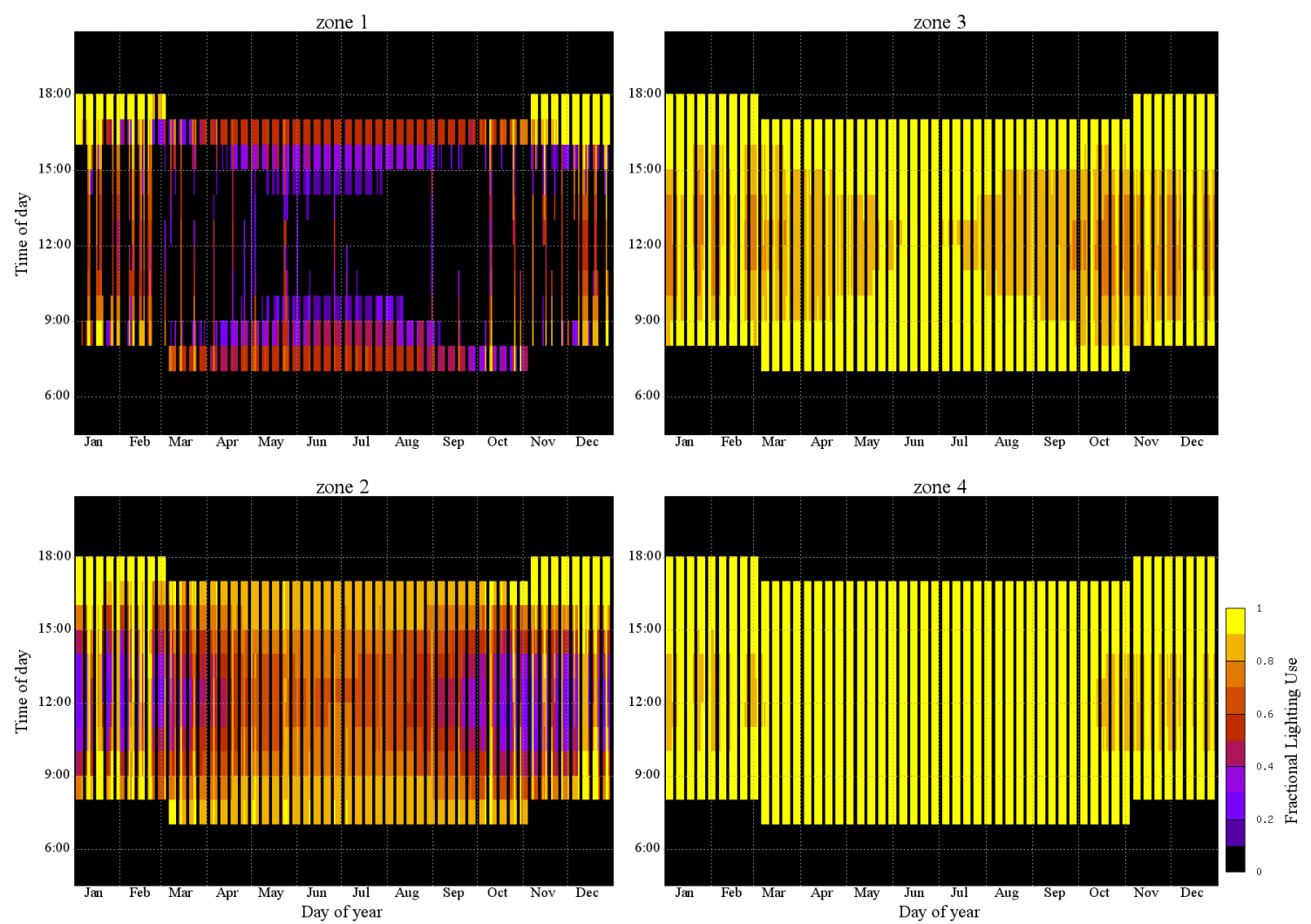

Fig. 13. Temporal plot of fractional lighting energy use in each zone for the reference case with a Venetian blind. Zone $1=0$ $10 \mathrm{ft}$ from the window, zone $4=30-40 \mathrm{ft}$ from the window. South-facing perimeter zone in Sacramento, California. The vertical shift in the plots mark the transitions between Standard and Daylight Savings Time. 

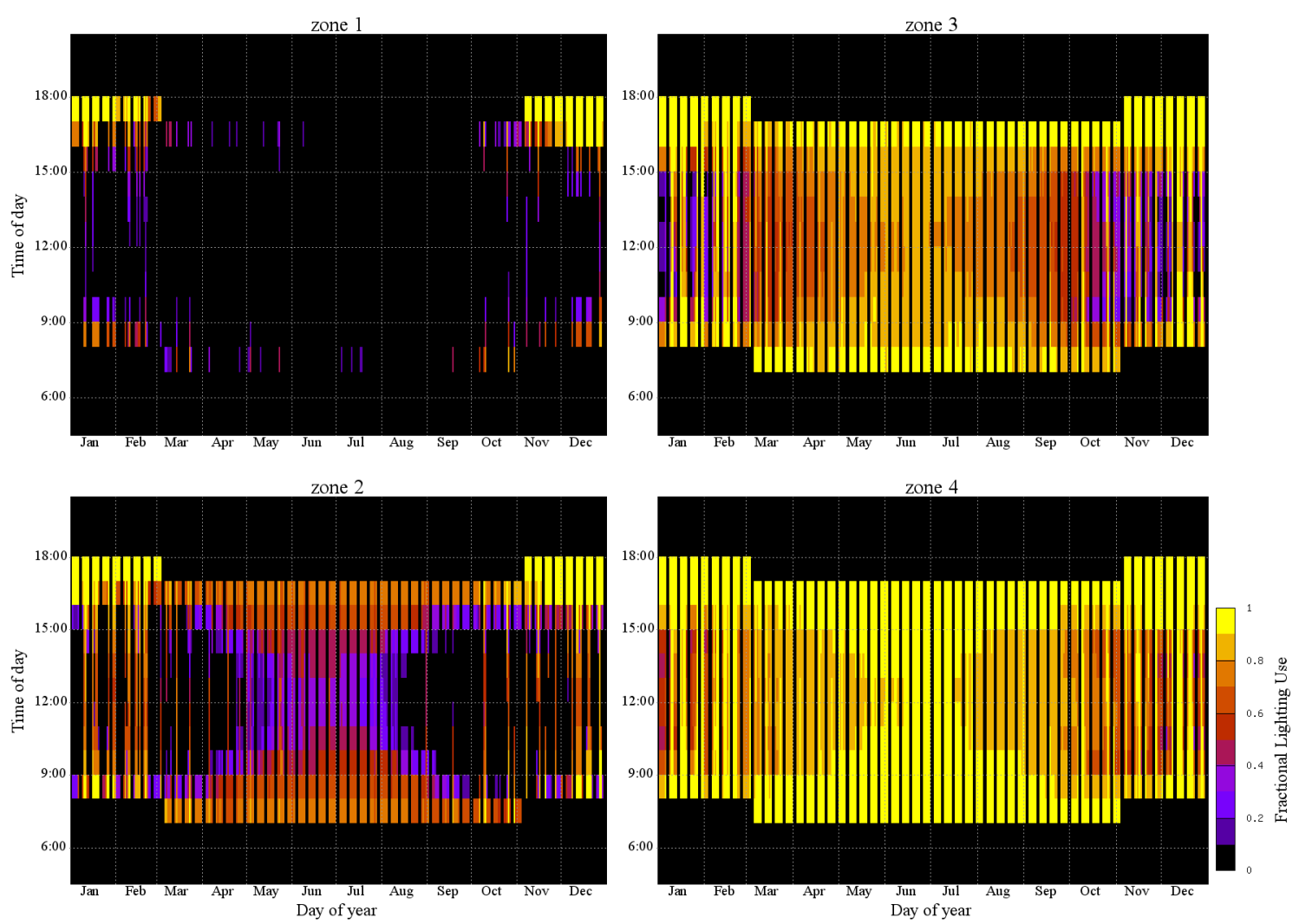

Fig. 14. Temporal plot of fractional lighting energy use in each zone for the P1 system.
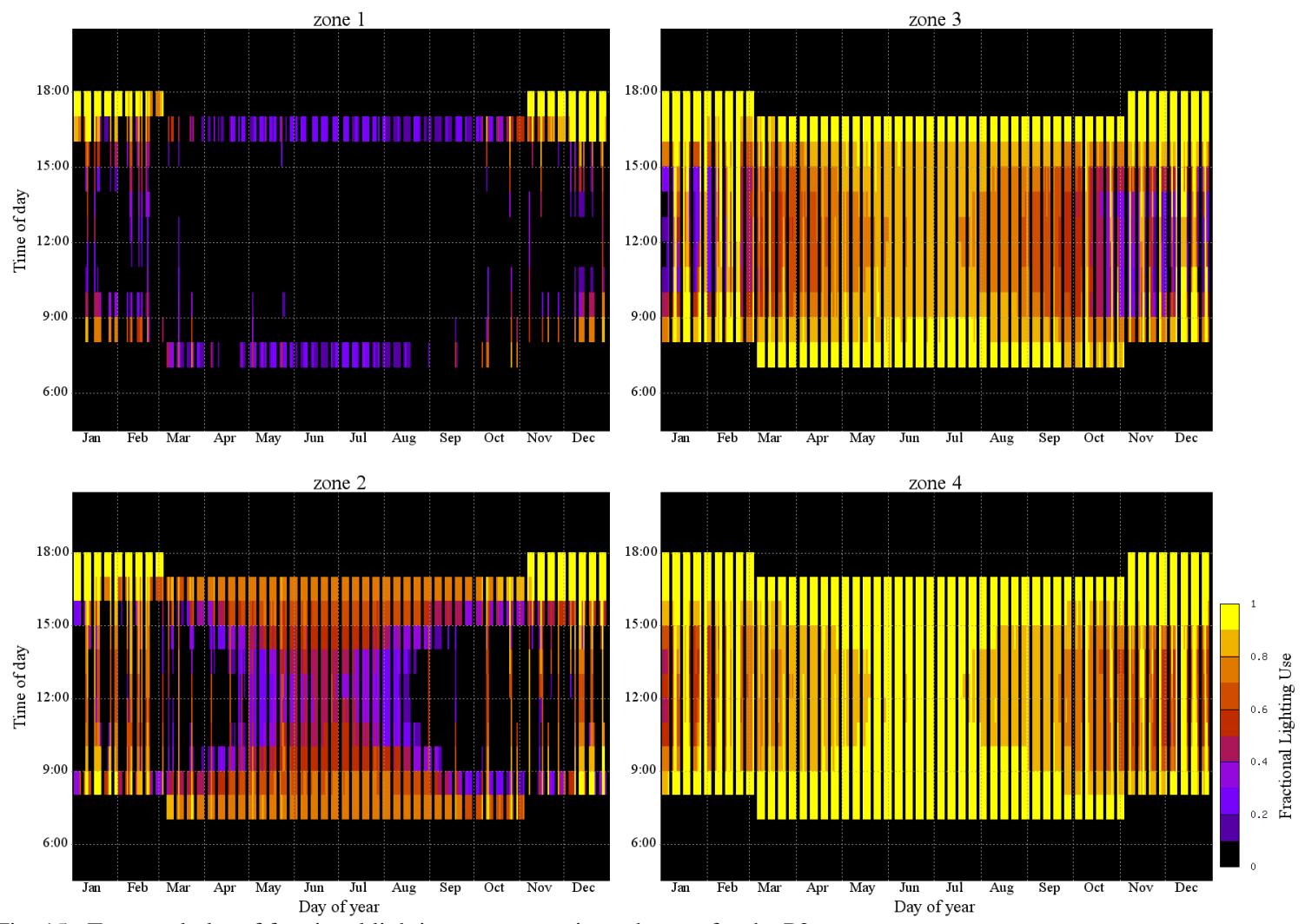

Fig. 15. Temporal plot of fractional lighting energy use in each zone for the P2 system. 


\subsubsection{Discomfort glare}

Table 7 contains the two DGP metrics used to determine visual comfort classes for each view (Weinold 2009). Temporal plots are given in Fig. 16-17 showing when glare occurred throughout the year for the south-facing window in the Sacramento climate. For the four views looking toward the sidewalls ranging in depth from the window, there were no hours when visual discomfort occurred. Similarly, a view from the front looking towards the rear wall yielded no occurrences of glare. For views looking at the window, discomfort glare occurred from October to February between 9:00-15:00 for both the P1 and P2 systems, with frequency increasing as the view position increased in distance from the window wall. Towards the rear, the level of adaptation is less due to the lower overall illuminance levels further from the window. For the period between the equinox and winter solstice, direct views of the orb of the sun are possible due to the low altitude angles of the sun.

Table 7

Comfort Class metrics. The first value is average DGP in the 5\% band, and second value is the DGP limit for $95 \%$ of office hours. Unshaded are comfort class A, light gray shade is comfort class B, and dark gray shading is comfort class C.

\begin{tabular}{|c|c|c|c|c|c|c|c|c|c|c|c|c|c|c|c|c|c|}
\hline & \multicolumn{4}{|c|}{ Burbank } & \multicolumn{4}{|c|}{ Chicago } & \multicolumn{4}{|c|}{ Houston } & \multicolumn{4}{|c|}{ Sacramento } \\
\hline & & \multicolumn{2}{|c|}{ S } & \multicolumn{2}{|c|}{ E } & \multicolumn{2}{|c|}{$\mathrm{S}$} & \multicolumn{2}{|c|}{ E } & \multicolumn{2}{|c|}{$\mathrm{S}$} & \multicolumn{2}{|c|}{ E } & \multicolumn{2}{|c|}{$\mathrm{S}$} & \multicolumn{2}{|c|}{ E } \\
\hline \multirow{3}{*}{ v1a } & P1 & 0.34 & 0.33 & 0.31 & 0.30 & 0.33 & 0.31 & 0.31 & 0.28 & 0.33 & 0.31 & & 0.29 & & 0.33 & 0.34 & 0.33 \\
\hline & $\mathrm{P} 2$ & 31 & 0.31 & 0.29 & 0.28 & 0.31 & 0.30 & 0.29 & 0.27 & 0.31 & 0.29 & 0.28 & 0.27 & 0.31 & 0.3 & & 0.31 \\
\hline & VB & 22 & 0.22 & 0.21 & 0.21 & .22 & 0.21 & 0.21 & 0.21 & .22 & 0.21 & 0.21 & 0.21 & .22 & 0.22 & 0.22 & 0.22 \\
\hline \multirow{3}{*}{$\mathrm{v} 1 \mathrm{~b}$} & P1 & .42 & 0.41 & 0.41 & 0.39 & 0.42 & 0.40 & 0.40 & 0.38 & 40 & 0.38 & 0.43 & 0.39 & 1.42 & 0.41 & .45 & 0.42 \\
\hline & $\mathrm{P} 2$ & 40 & 0.39 & 0.39 & 0.37 & .41 & 0.38 & 0.38 & 0.36 & 0.38 & 0.36 & 0.40 & 0.37 & .40 & 0.39 & 0.43 & 0.41 \\
\hline & VB & 0.29 & 0.28 & 0.27 & 0.27 & 0.28 & 0.27 & 0.27 & 0.26 & 0.28 & 0.26 & 0.27 & 0.26 & 0.29 & 0.28 & 0.29 & 0.28 \\
\hline \multirow{3}{*}{$\mathrm{v} 1 \mathrm{c}$} & P1 & 23 & 0.23 & 0.23 & 0.22 & 0.23 & 0.22 & 0.22 & 0.21 & 0.22 & 0.21 & 0.22 & 0.21 & .23 & 0.23 & 0.24 & 0.23 \\
\hline & P2 & 22 & 0.22 & 0.22 & 0.21 & 0.22 & 0.21 & 0.21 & 0.21 & 0.22 & 0.21 & 0.21 & 0.20 & 0.22 & 0.22 & 0.23 & 0.22 \\
\hline & VB & .18 & 0.18 & 0.18 & 0.18 & 0.18 & 0.18 & 0.18 & 0.18 & 0.18 & 0.18 & 0.18 & 0.18 & 0.18 & 0.18 & 0.18 & 0.18 \\
\hline \multirow{3}{*}{$\mathrm{v} 2 \mathrm{a}$} & P1 & .31 & 0.24 & 0.22 & 0.21 & 0.29 & 0.23 & 0.21 & 0.21 & 0.27 & 0.22 & 0.22 & 0.21 & 0.31 & 0.26 & 0.23 & 0.22 \\
\hline & $\mathrm{P} 2$ & 25 & 0.24 & 0.22 & 0.21 & 0.25 & 0.23 & 0.21 & 0.21 & 0.24 & 0.22 & 0.22 & 0.21 & 0.26 & 0.23 & 0.23 & 0.21 \\
\hline & VB & 0.19 & 0.19 & 0.19 & 0.18 & 0.19 & 0.18 & 0.18 & 0.18 & 0.19 & 0.18 & 0.18 & 0.18 & 0.19 & 0.19 & 0.19 & 0.19 \\
\hline \multirow{3}{*}{$\mathrm{v} 2 \mathrm{~b}$} & $\overline{\mathrm{P} 1}$ & 37 & 0.36 & 0.40 & 0.36 & 0.40 & 0.36 & 0.37 & 0.33 & 0.35 & 0.33 & 0.41 & 0.36 & 0.39 & 0.37 & 0.43 & 0.39 \\
\hline & $\mathrm{P} 2$ & 36 & 0.35 & 0.37 & 0.34 & 0.38 & 0.35 & 0.35 & 0.32 & 0.33 & 0.32 & 0.38 & 0.35 & 0.38 & 0.36 & 0.40 & 0.37 \\
\hline & VB & 24 & 0.24 & 0.23 & 0.23 & 0.24 & 0.23 & 0.23 & 0.23 & 0.23 & 0.23 & 0.23 & 0.22 & 0.24 & 0.23 & 0.24 & 0.24 \\
\hline \multirow{3}{*}{ v3a } & $\mathrm{P} 1$ & 31 & 0.22 & 0.21 & 0.20 & 0.29 & 0.22 & 0.20 & 0.19 & 0.25 & 0.21 & 0.23 & 0.21 & .30 & 0.22 & 0.21 & 0.20 \\
\hline & $\mathrm{P} 2$ & 24 & 0.22 & 0.21 & 0.20 & 0.25 & 0.22 & 0.20 & 0.1 & 0.22 & 0.21 & 0.23 & 0.20 & 0.25 & 0.23 & 0.22 & 0.20 \\
\hline & VB & 19 & 0.19 & 0.19 & 0.18 & 0.19 & 0.18 & 0.18 & 0.18 & 0.18 & 0.18 & 0.19 & 0.18 & 0.19 & 0.19 & 0.19 & 0.19 \\
\hline \multirow{3}{*}{$\mathrm{v} 3 \mathrm{~b}$} & P1 & 37 & 0.32 & 0.38 & 0.31 & 0.39 & 0.33 & 0.35 & 0.29 & 0.32 & 0.29 & 0.39 & 0.32 & 0.40 & 0.35 & 0.41 & 0.35 \\
\hline & P2 & 34 & 0.32 & 0.34 & 0.31 & 0.36 & 0.32 & 0.33 & 0.30 & 0.30 & 0.29 & 0.35 & 0.32 & 0.35 & 0.33 & 0.37 & 0.34 \\
\hline & VB & 0.24 & 0.24 & 0.24 & 0.24 & 0.24 & 0.24 & 0.24 & 0.24 & 0.24 & 0.24 & 0.24 & 0.24 & 0.24 & 0.24 & 0.25 & 0.24 \\
\hline \multirow{3}{*}{$\mathrm{v} 4 \mathrm{a}$} & P1 & 0.26 & 0.22 & 0.21 & 0.20 & 0.27 & 0.22 & 0.20 & 0.19 & 0.22 & 0.21 & 0.23 & 0.22 & 0.27 & 0.22 & 0.22 & 0.20 \\
\hline & P2 & 24 & 0.22 & 0.22 & 0.20 & 0.25 & 0.22 & 0.21 & 0.20 & 0.22 & 0.21 & 0.23 & 0.21 & 0.25 & 0.22 & 0.22 & 0.20 \\
\hline & VB & 18 & 0.18 & 0.18 & 0.18 & 0.18 & 0.18 & 0.18 & 0.18 & 0.18 & 0.18 & 0.18 & 0.17 & 0.18 & 0.18 & 0.18 & 0.18 \\
\hline \multirow{3}{*}{$\mathrm{v} 4 \mathrm{~b}$} & P1 & 33 & 0.29 & 0.36 & 0.30 & 0.37 & 0.31 & 0.33 & 0.28 & 0.29 & 0.28 & 0.37 & 0.32 & 0.37 & 0.32 & 0.39 & 0.33 \\
\hline & $\mathrm{P} 2$ & & 0.30 & 0.33 & 0.3 & 0.34 & 0.31 & 0.32 & 0.2 & 0.29 & 0.28 & 0.34 & 0.31 & 0.34 & 0.32 & 0.36 & 0.33 \\
\hline & VB & 0.25 & 0.25 & 0.25 & 0.25 & 0.25 & 0.25 & 0.25 & 0.25 & 0.25 & 0.25 & 0.25 & 0.25 & 0.25 & 0.25 & 0.25 & 0.25 \\
\hline
\end{tabular}



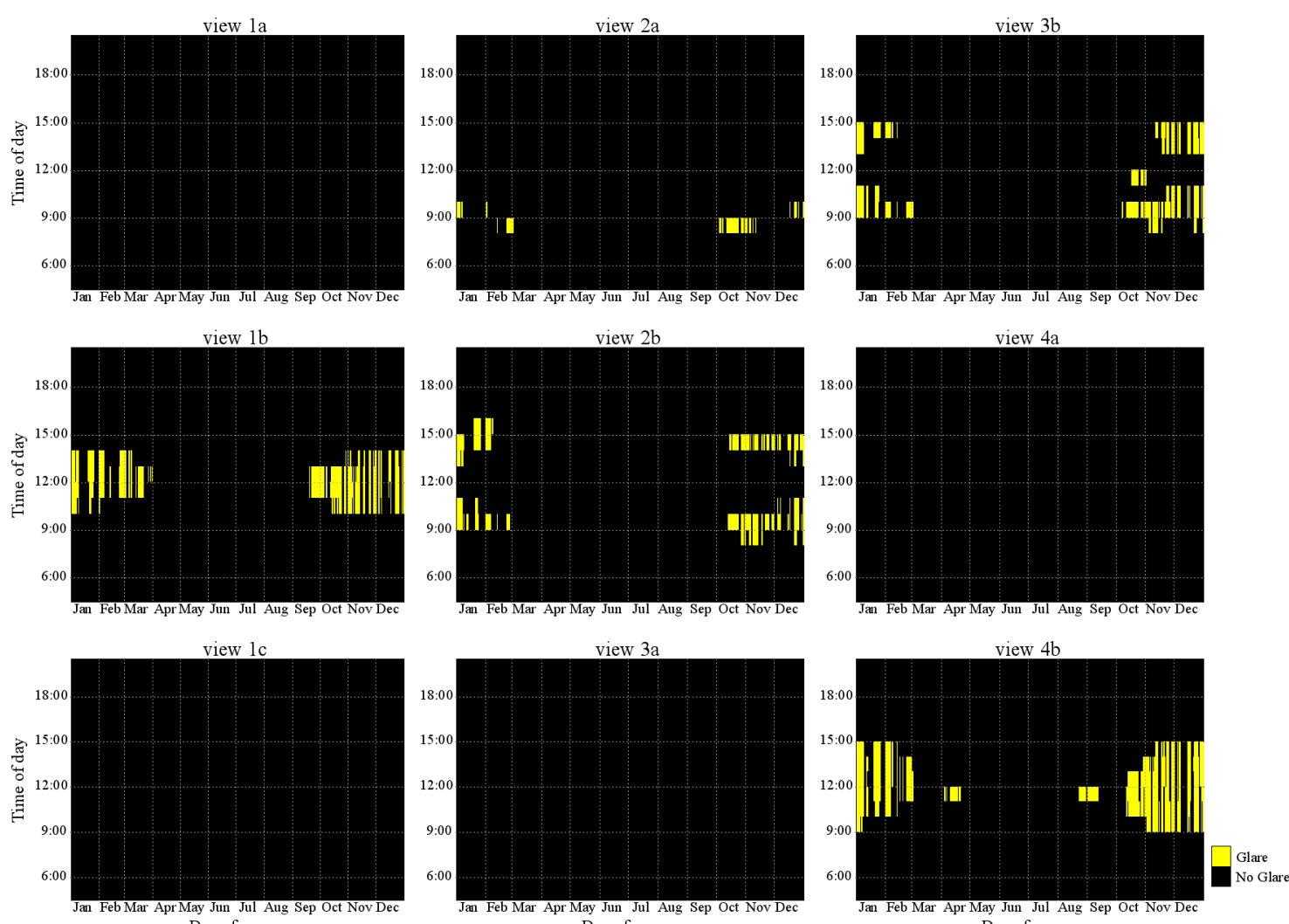

Fig. 16. Temporal plots of glare occurrence for Sacramento, south facing façade, P1.
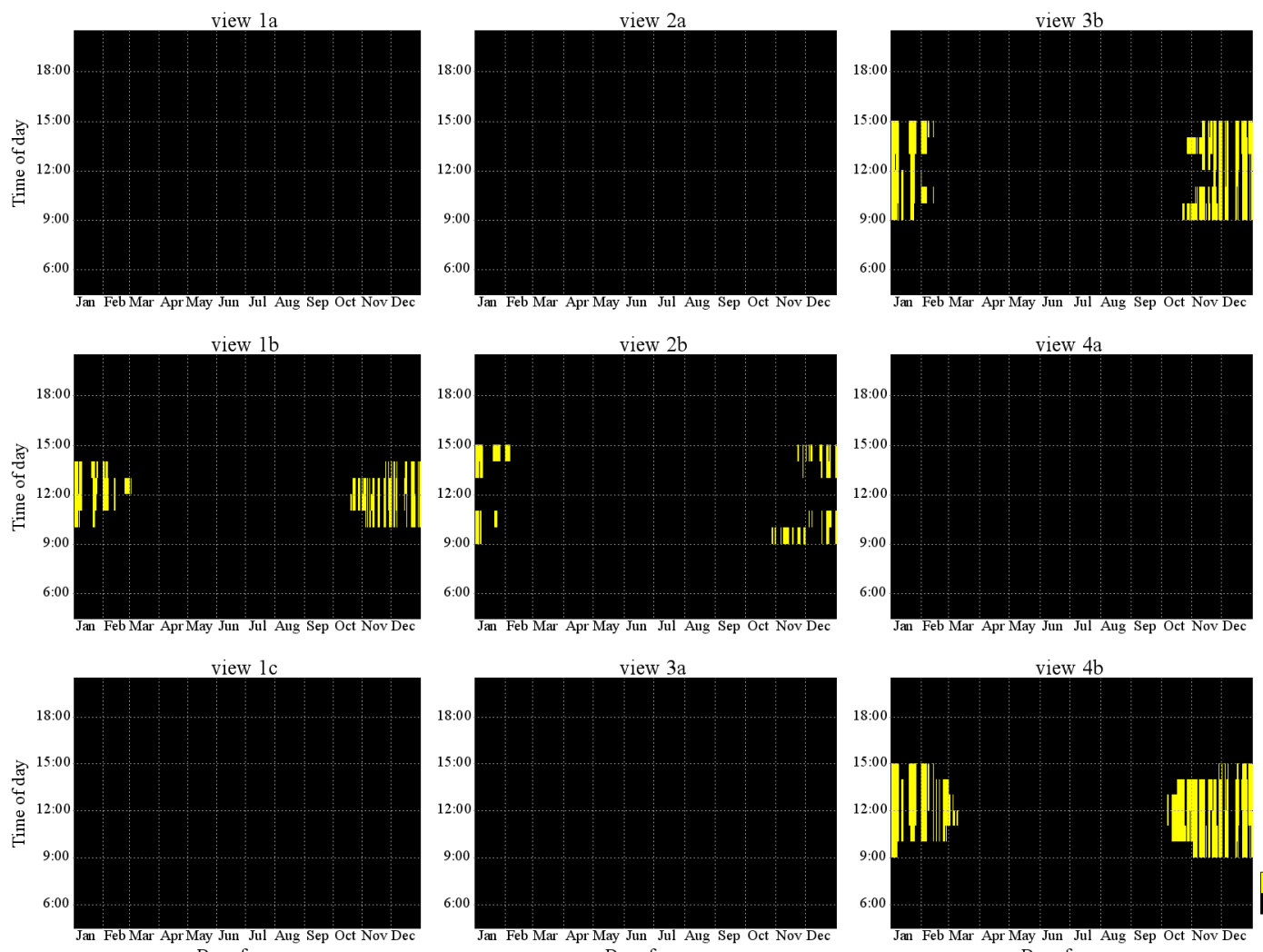

Jan Feb Mar Apr May Jun Jor An

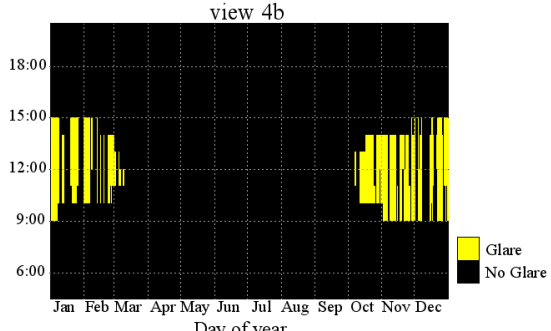

Fig. 17. Temporal plots of glare occurrence for Sacramento, south facing façade, P2. 
The overall performance of the systems can be more easily compared on a scatter plot with the glare and energy use performance metrics on each axis. Figure 18 shows the performance for the four simulation cases (considering the 0-40 ft perimeter zone) including a commercially-available specularly-reflecting louver system ("C1") that was studied earlier (McNeil and Lee, 2013). The $\mathrm{C} 1$ and reference Venetian blind systems produced no visual discomfort, however the P1 and P2 systems yielded the greatest annual energy savings.
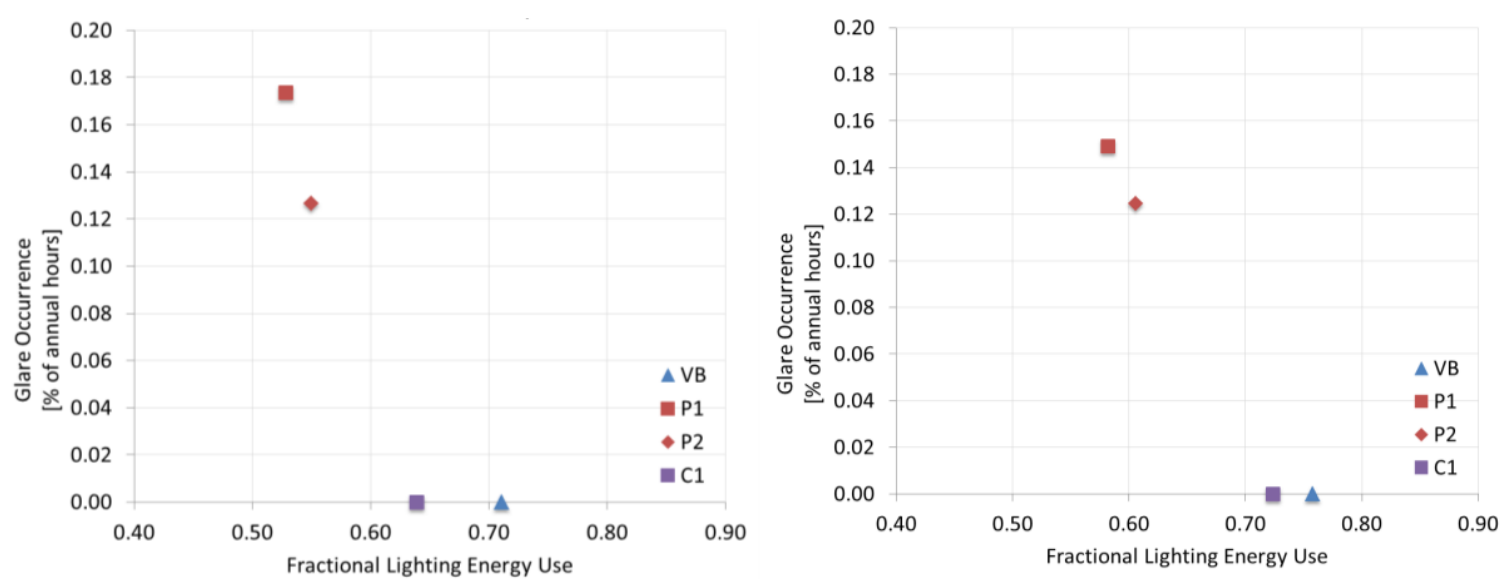

Fig. 18. Fractional lighting energy use for the south (left) and east (right) facing perimeter zone versus percentage of glare occurrence in a year. The $\mathrm{C} 1$ system is a commercially available daylight-redirecting product. Data are given for the $40 \mathrm{ft}$ deep zone in Sacramento, California.

\section{Conclusions}

A microstructured, asymmetrical, multi-sided refractive prismatic film was fabricated with an orderly array of linear protrusions between 50-250 micrometers high. The film was designed to be adhered to the surface of a vertical clerestory window so that incident daylight would be redirected upwards towards the ceiling plane and then diffused to the work areas below. The performance of the film was evaluated to determine lighting energy use savings and occurrence of discomfort glare in a $12.2 \mathrm{~m}(40 \mathrm{ft})$ deep, open plan office with 1-m (3.3 ft) high partitioned workstations.

Limited scanning goniophotometric measurements were taken of the film. Two profiles were traced from optical scans of the fabricated film and these two profiles and the original design were modeled using the Radiance genBSDF ray-tracing tool to generate an average synthetic BSDF dataset that was used for the simulations. The synthesized BSDF dataset agreed largely with measured data: in-plane directhemispherical intensities agreed well across the range of near normal incident angles $\left(\theta_{\mathrm{i}}=0-60^{\circ}, \varphi_{\mathrm{i}}=90^{\circ}\right)$, with greater experimental noise occurring for $\theta$ values near $90^{\circ}$. The peak transmitted energy was found to occur in the same outgoing patch for incident angles between $20-70^{\circ}$.

For a single incident direction, relative differences in average workplane illuminance produced by the measured versus synthetic BSDF datasets were low in the first two zones and more significant in the zones further from the window. Ceiling luminance was also significantly greater with the synthetic BSDF dataset. The differences were considered to be local and random and were likely to be averaged out when all other angles of incidence over the incoming hemisphere were considered.

In terms of light redirecting performance, the goniophotometric data indicated that for $\varphi_{\mathrm{i}}$ angles between $45^{\circ}$ and $135^{\circ}$ (since the system is axially symmetric), the microstructured film was able to achieve low outgoing angles of redirection when the sun or incoming light was within $\theta_{\mathrm{i}}$ incident angles between about $18-35^{\circ}$. These angles correspond roughly to mid-day hours $( \pm 2-3 \mathrm{~h})$ for a south-facing façade and equinox to winter solstice solar altitudes for US latitudes of about $40^{\circ} \mathrm{N}$ and a slightly broader range of hours for 
more northern latitudes. Results from annual simulations of lighting energy use using Radiance simulation tools confirmed these trends.

Time-efficient simulation capabilities were applied, where BSDF data were used with the Radiance threephase matrix calculation approach to determine annual performance. A variant of the Klems basis was defined so that flux was assigned to patches above and below the horizon, enabling more accurate evaluations of glare. The window film was modeled in two configurations: the P1 system was defined with the prismatic film adhered to the \#4 surface of an insulating glass unit while the P2 system was defined as a triple-pane system with an outboard low-e glazing layer and two clear glass layers with the prismatic film adhered to surface \#4 and a second diffusing film adhered to surface \#5. Simulations were conducted to evaluate glare discomfort from nine viewpoints looking at the side wall, window, and rear wall of the perimeter zone.

Annual lighting energy savings produced by the P2 system ranged from $39-43 \%$ in a $12.2 \mathrm{~m}$ (40 ft) deep south facing perimeter zone in north and south regions of the U.S., where the reference case was defined with no lighting controls. Compared to a south-facing perimeter zone with Venetian blinds and daylighting controls, lighting energy savings were 20-22\%. Estimated simple payback ranged from two to six years.

For viewpoints within the space located both near and looking normal to the window, the P1 and P2 systems were found to produce visual discomfort (DGP Classes B and C) for all climates and window orientations. Discomfort glare occurred during equinox to winter mid-day hour when the sun angle was low and the orb of the sun was within the occupant's direct field of view. The P2 system spread out and reduced the intensity of the sun, reducing glare discomfort compared to the P1 system.

Several challenges were identified over the course of this study that led to further developments in both measurement and modeling tools and raised awareness of the broader issues faced by the buildings industry. First, goniophotometric measurements to generate full BSDF datasets take time. In this study, collection of data at different phi angles had to be implemented manually, hindering iterative R\&D activities that rely on feedback from performance evaluations. A sample rotator was subsequently added to the goniophotometer, significantly reducing the time needed to collect BSDF data for a single incident direction. For each sample, 145 incident directions must be measured for anisotropic samples (half that for anisotropic samples with right-left symmetry as was the case of the prismatic film). Interpolation tools were also subsequently developed that enable one to significantly reduce the requisite number of incident angles with minimal differences in relative error (Ward et al. 2012). Further work is underway to test and validate these tools.

Second, the three-phase method has been shown to be adequate for evaluations of spatially-averaged workplane illuminance and annualized metrics in prior validation studies but use of this method to evaluate discomfort glare from daylighting systems is known to have accuracy limitations. Balancing trade-offs between daylighting and glare performance was a key issue in the development of these prototype systems and is critical for assessments of fenestration designs in general. A five-phase method (McNeil 2013) with variable resolution BSDF datasets (Ward et al. 2012) was subsequently derived to increase accuracy, where the sky component is calculated separately from the sun component, enabling the sun component to be modeled with high-resolution BSDF data that captures the peak intensities of transmitted flux. Variable resolution BSDF datasets provide high resolution data in areas of the transmittance distribution where significant changes in intensity occur and low resolution data in areas where changes are minimal (e.g., as in Fig. 6). Further work is underway to test and validate the five-phase method as well.

Third, quality of measured and synthetic BSDF data has been and continues to be a critical issue. The scanning goniophotometer used in this study is a unique instrument of which there are only a handful in the world. There are also commercial imaging goniophotometers with more limited dynamic range and resolution available to industry. Some work has been done to compare measurements taken with different devices (Krehel et al., 2015). Synthetic BSDF datasets can be generated using open source Radiance 
software by architects and engineers for simulation studies. In the case of early prototype developments, synthetic data may be the only source of data. Additional work is needed to define appropriate methods to ensure quality of data not only for lighting energy and solar heat gain calculations (Klems 145x145 basis) but also for visual comfort assessments (variable resolution basis).

With these and other future advances in measurement and simulation capabilities, we anticipate more accurate results that will support a more rapid design-evaluation cycle for developers of new emerging technologies and possibly accelerated market adoption with greater confidence and lowered perceived risk.

\section{Acknowledgments}

We would like to thank Raghunath Padiyath, Doug Huntley, and Bing Hao at the 3M Renewable Energy Division for their technical support on this project.

This work was supported by the Assistant Secretary for Energy Efficiency and Renewable Energy, Building Technologies Program of the U.S. Department of Energy under Contract No. DE-AC02-

05CH11231 and by the California Energy Commission through its Public Interest Energy Research (PIER) Program on behalf of the citizens of California.

This research used the Lawrencium computational cluster resource provided by the IT Division at the Lawrence Berkeley National Laboratory (supported by the Director, Office of Science, Office of Basic Energy Sciences, of the U.S. Department of Energy under Contract No. DE-AC02-05CH11231).

\section{References}

American Society of Heating, Refrigerating and Air-Conditioning Engineers, Inc., 2001. ANSI/ASHRAE/IES Standard 90.1-2001 Energy Standard for Buildings except Low-Rise Residential Buildings. ASHRAE, Inc.: Atlanta, Georgia.

American Society of Heating, Refrigerating and Air-Conditioning Engineers, Inc., 2010.

ANSI/ASHRAE/IES Standard 90.1-2001 Energy Standard for Buildings except Low-Rise Residential Buildings. ASHRAE, Inc.: Atlanta, GA.

Andersen, M., Rubin, M., Powles, R., Scartezzini, J.-L., 2005. Bi-directional transmission properties of Venetian blinds: experimental assessment compared to ray-tracing calculations. Solar Energy 78: 187-198.

Andersen, M., de Boer, J., 2006. Goniophotometry and assessment of bidirectional photometric properties of complex fenestration systems. Energy and Buildings 38: 836-848.

Andersen, M., Stokes, E., Gayeski, N., Browne, C., 2010. Using digital imaging to assess spectral solaroptical properties of complex fenestration materials: A new approach in video-goniophotometry. Solar Energy 84 (4): 549-562.

Andersen, M., Thuot, K.W., 2012. A passive louver-based daylighting system. US Patent publication WO2012068104 A1, application PCT/US2011/060784, May 24.

Apian-Bennewitz, P., von der Hardt, J., 1998. Enhancing and calibrating a goniophotometer. Solar Energy Materials and Solar Cells 54: 309-322.

Apian-Bennewitz, P., 2010. New scanning gonio-photometer for extended BRTF measurements. Proc. SPIE 7792, 77920O, Reflection, Scattering, and Diffraction from Surfaces II, September 1, 2010.

Bartenbach, C., Möeller, M., Lanzenberger, R., 1987. Arrangement for illuminating a room with daylight, US Patent 4,699,467, October 13. 
Bartenbach, C., 1994. Venetian blind. Patents EP0400662 B1, DE59004468D1, EP0400662A1, February 2.

Beltrán, L.O., Lee, E.S., Selkowitz, S.E., 1997. Advanced optical daylighting systems: Light shelves and light pipes. Journal of the Illuminating Engineering Society 26(2):91-106.

California Energy Commission, 2012. 2013 Building Energy Efficiency Standards: Title 24, Part 6, and Associated Administrative Regulations in Part 1. CEC-400-2012-004-CMF.

Deru, M., Field, K., Studer, D., Benne, K., Griffith, B., Torcellini, P., Halverson, M., Winiarski, D., Liu, B., Rosenberg, M., Huang, J., Yazdanian, M., Crawley, D., U.S. Department of Energy Commercial Reference Building Models of the National Building Stock. Washington, DC: U.S. Department of Energy, Energy Efficiency and Renewable Energy, Office of Building Technologies. Technical Report NREL/TP5500-46861, National Renewable Energy Laboratory, February 2011.

D\&R International, Ltd., 2012. Buildings Energy Data Book, Table 1.1.5, p. 1-3 and Table 3.1.5, p. 3-3. Prepared by: D\&R International, Ltd. under contract to Pacific Northwest National Laboratory 2012 for the US Department of Energy, Office of Energy Efficiency and Renewable Energy, Building Technologies Program. Washington, DC. http://buildingsdatabook.eren.doe.gov/

Grobe, L.O, Wittkopf, S., Apian-Bennewitz, P., Jonsson, J.C., Rubin, M.D., 2010. Experimental validation of bidirectional reflection and transmission distribution measurements of specular and scattering materials. Proc. SPIE 7725, 772510 (2010).

Hao, B., Marttila, C., Padiyath, R., 2012. Hybrid Light Redirecting And Light Diffusing Constructions. US Patent WO2012134787 A3, Application PCT/US2012/028693, November 29.

Hirning MB, Isoardi GL, Coyne S, Garcia Hansen VT, Cowling I. 2013. Post occupancy evaluations relating to discomfort glare: A study of green buildings in Brisbane. Building and Environment 59 (2013): $349-357$.

Hopkinson, R.G., Bradley, R.C., 1960. Glare from very large sources. Illuminating Engineering (55): 288297.

Klems, J.H., 1994a. A new method for predicting the solar heat gain of complex fenestration systems: I. Overview and derivation of the matrix layer calculation, ASHRAE Transactions 100 (1): 1065-1072.

Klems, J.H., 1994b. A new method for predicting the solar heat gain of complex fenestration systems: II. Detailed description of the matrix layer calculation, ASHRAE Transactions 100 (1): 1073-1086.

Krehel, M., Kampf, J., Wittkopf, S., 2015. Characterisation and modelling of advanced daylight redirection systems with different goniophotometers. Proceedings from CISBAT 2015, Lausanne, Switzerland, September 9-11, 2015.

LBNL, 2013. International Glazing Database, http://windowoptics.lbl.gov/data/igdb (accessed April 15, 2016).

McNeil, A., Lee, E.S., 2012. A validation of the Radiance three-phase simulation method for modelling annual daylight performance of optically complex fenestration systems. Journal of Building Performance Simulation (July): 1-14.

McNeil, A., 2013. The five-phase method for simulating complex fenestration with Radiance. https://facades.lbl.gov/sites/all/files/tutorial-fivephasemethod.pdf (accessed April 15, 2016).

McNeil, A., C.J. Jonsson, D. Appelfeld, G. Ward, E.S. Lee, 2013. A validation of a ray-tracing tool used to generate bi-directional scattering distribution functions for complex fenestration systems. Solar Energy 98 (2013): 404-414. 
McNeil, A., E.S. Lee, 2013, Annual daylighting performance of a passive optical light shelf in sidelit perimeter zones of commercial buildings,

https://facades.lbl.gov/sites/all/files/passive_optical_light_shelf.pdf (accessed April 15, 2016).

Moench, J., Rentzsch, H., Lang, G., Mueller, H., 1987. Device for guiding daylight, US Patent 4,654,243

(Siemens), March 31.

Mitchell, R., Kohler, C., Klems, J., Rubin, M., Arasteh, D., Huizenga, C., Yu, T. Curcija, D., 2008. Window 6.2/ Therm 6.2 Research Version User Manual, Lawrence Berkeley National Laboratory, LBNL941. Available http://windows.lbl.gov/software/window/window.html (accessed April 15, 2016).

Molina, G., Bustamante, W., Rao, J., Fazio, P., Vera, S., 2015. Evaluation of Radiance's genBSDF capability to assess solar bidirectional properties of complex fenestration systems. Journal of Building Performance Simulation (8) 4: 216-225.

Muhs, J.D., Earl, D.D., Beshears, D.L., Masey, L.C., Jordan, J.K., Lind, R.F., 2007. Hybrid solar lighting systems and components. US Patent 7,231,128 B2, June 12.

Padiyath, R., Marttila, C., Nestegard, M., 2013. Light redirecting constructions, US Patent Publication 2013/0038928 A1, February 14.

Papamichael, K., Beltrán, L., Furler, R., Lee, E.S., Selkowitz, S.E., Rubin, M., 1994. The energy performance of prototype holographic glazings. Proceedings of the SPIE International Symposium on Optical Materials Technology for Energy Efficiency and Solar Energy Conversion XIII, Freiburg, Germany.

Rea, M., 2002. "IESNA Handbook 9th edition." The Illuminating Engineering Society of North America, USA.

Rogers, Z.L., Holtz, M.J., Clevenger, C.M., Digert, N.E., 2004. Mini-optical light shelf daylighting system. US Patent US6714352 B2, March 30.

Ruck, N. with Aschehoug, O., Aydinli, S., Christoffersen, J., Courret, G., Edmonds, I., Jakobiak, R., Kischkoweit-Lopin, M., Klinger, M., Lee, E.S., Michel, L., Scartezzini, J.L., Selkowitz. S.E., 2000. Daylight in buildings: A source book on daylighting systems and components. https://facades.lbl.gov/sites/all/files/daylight-in-buildings.pdf, accessed April 15, 2016.

Smith, G.B., Granqvist, C.-G.S., 2010. Green nanotechnology: Solutions for sustainability and energy in the built environment. Boca Raton, Florida: CRC Press, Taylor \& Francis Group.

Sullivan, R., Beltrán, L., Lee, E.S., Rubin, M., Selkowitz, S.E., 1998. Energy and daylight performance of angular selective glazings. Proceedings of the Thermal Performance of the Exterior Envelopes of Buildings VII, Clearwater Beach, Florida.

Thanachareonkit, A., E.S. Lee, A. McNeil, 2014, Empirical assessment of a prismatic daylight-redirecting window film in a full-scale office testbed. Leukos: The Journal of the Illuminating Engineering Society of North America 10 (1): 19-45.

Wadsworth, F., 1903. Illuminating prism structure, US Patent 720,386, February 10.

Ward Larson, G. and Shakespeare, R., 1998, Rendering with Radiance: The Art and Science of Lighting Visualization. San Francisco: Morgan Kaufmann.

Ward, G., Mistrick, R., Lee, E.S., McNeil, A. Jonsson, J., 2011. Simulating the Daylight Performance of Complex Fenestration Systems Using Bidirectional Scattering Distribution Functions within Radiance. Leukos 7(4): 241-261. 
Ward, Gregory J., Murat Kurt, Nicolas Bonneel, 2012, A Practical Framework for Sharing and Rendering Real-World Bidirectional Scattering Distribution Functions, 2012. http://eetd.lbl.gov/publications/apractical-framework-for-sharing-and (accessed April 15, 2016).

Whitehead, L.A., 2013. Sunlight redirecting mirror arrays. US Patent Publication WO2013059908 A1, Application PCT/CA2012/000854, May 2.

Wienold, J., Christoffersen, J., 2006. Evaluation methods and development of a new glare prediction model for daylight environments with the use of CCD cameras. Energy and Buildings 38 (7): 734-757.

Wienold, J., 2009. Dynamic daylight glare evaluation, Building Simulation 2009, $11^{\text {th }}$ International IBPSA Conference, Glasgow, Scotland, July 27-30.

Wienold, J., 2012. evalglare version 1.0, September 2012, Fraunhofer Institute for Solar Energy Systems, Freiburg, Germany. 